\title{
Origin, Differentiation, and Function of Intestinal Macrophages
}

\author{
Calum C. Bain* and Anika Schridde \\ Centre for Inflammation Research, University of Edinburgh, Edinburgh, United Kingdom
}

Macrophages are increasingly recognized as essential players in the maintenance of intestinal homeostasis and as key sentinels of the intestinal immune system. However, somewhat paradoxically, they are also implicated in chronic pathologies of the gastrointestinal tract, such as inflammatory bowel disease (IBD) and are therefore considered potential targets for novel therapies. In this review, we will discuss recent advances in our understanding of intestinal macrophage heterogeneity, their ontogeny and the potential factors that regulate their origin. We will describe how the local environment of the intestine imprints the phenotypic and functional identity of the macrophage compartment, and how this changes during intestinal inflammation and infection. Finally, we highlight key outstanding questions that should be the focus of future research.

\section{OPEN ACCESS}

Edited by:

Mats Bemark

University of Gothenburg, Sweden

Reviewed by:

Diane Bimczok,

Montana State University,

United States

Arthur Mortha

University of Toronto, Canada

*Correspondence:

Calum C. Bain

calum.bain@ed.ac.uk

Specialty section:

This article was submitted to

Mucosal Immunity,

a section of the journal

Frontiers in Immunology

Received: 16 June 2018 Accepted: 06 November 2018 Published: 27 November 2018

Citation:

Bain CC and Schridde A (2018) Origin, Differentiation, and Function of

Intestinal Macrophages.

Front. Immunol. 9:2733.

do: 10.3389/fimmu.2018.02733
Keywords: macrophage, monocyte, intestine, inflammation, colitis, ontogeny

\section{INTRODUCTION}

The gastrointestinal tract faces an unrivaled exposure to foreign antigens and, as a result, is home to the largest compartment of the immune system. This includes a network of mononuclear phagocytes (MPs), including macrophages and conventional dendritic cells (cDCs), that play distinct yet complementary roles in discriminating between innocuous antigens and potential pathogens, ensuring that the appropriate response is mounted to each. While this is a highly efficient process, it can break down in some individuals, leading to the development of chronic inflammation, such as inflammatory bowel disease (IBD) in which inappropriate immune responses are mounted against the commensal microbiota. Thus, there is great interest in understanding the biology of intestinal MPs. The role of macrophages in health and disease has attracted particular attention, as their plasticity and wound healing capabilities make them attractive targets for potential novel therapies to treat IBD. In this article, we will first discuss the current understanding of macrophage heterogeneity in the gut wall, before describing the roles macrophages play in intestinal homeostasis and how this may depend on their anatomical positioning. We will then review the recent developments in intestinal macrophage ontogeny, discussing how the local environment of the gut imprints the phenotypic and functional identity of macrophages, before finally describing the changes that occur when homeostasis is perturbed by inflammation.

\section{IDENTIFYING MACROPHAGES IN THE GUT WALL}

One of the major issues that has stifled our progress on understanding the immunobiology of intestinal macrophages is their inaccurate identification. For instance, although murine macrophages have traditionally been identified based on their expression of the pan-macrophage 
marker F4/80 (1), it is clear that other cells, such as conventional dendritic cells (cDCs) and eosinophils can express F4/80 to some extent $(2,3)$. Furthermore, many macrophages, including those in the intestine, express high levels of CD11c and MHCII, markers that have classically been used to identify cDCs (3). Thus, the identification of intestinal macrophages requires a multi-parameter approach. The Mer tyrosine kinase (MerTK) and the high affinity Fc $\gamma$ R1 (CD64), have emerged as superior markers for the identification of macrophages across different tissues (4-6), the latter also being useful across species (7-10). When used in combination with CD11c and MHCII, CD64 expression distinguishes macrophages from bona fide $\mathrm{CDC}$ in the gut wall $(5,10,11)$. This is corroborated by the distinct growth factor dependency and migration patterns of CD64defined MPs. Whereas CD64 ${ }^{+}$MPs are highly dependent on colony stimulating factor 1 (CSF1; also known as M-CSF) for

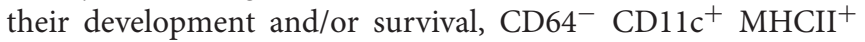
MPs, but not $\mathrm{CD}^{+} 4^{+} \mathrm{MPs}$, are highly dependent on the $\mathrm{CDC}$ specific growth factor Flt3L $(10,11)$. Consistently, CD64$\mathrm{CD}_{11 \mathrm{c}^{+}} \mathrm{MHCII}^{+} \mathrm{MPs}$ have been shown to continually migrate to the mesenteric lymph nodes in a CCR7-dependent manner to participate in $\mathrm{T}$ cell priming $(10,12-14)$, defining features of cDC. In contrast, $\mathrm{CD}^{+} 4^{+} \mathrm{MPs}$ are non-migratory and display characteristic macrophage morphology, with abundant cytoplasm and cytoplasmic vacuoles $(9,15,16)$. Thus, by multiple criteria, $\mathrm{CD}_{64}^{-}{ }^{-} \mathrm{CD} 11 \mathrm{c}^{+} \mathrm{MHCII}^{+} \mathrm{MPs}$ and $\mathrm{CD} 64^{+}$MPs fit the definition of $\mathrm{CDC}$ and macrophages, respectively. One additional feature of murine intestinal macrophages that distinguishes them from $\mathrm{CDC}$ is their high expression of the chemokine receptor CX3CR1 $(9,15,17-20)$. Indeed, by using $C \times 3 c r 1^{+/ g f p}$ knock-in mice (21), mature CX3CR $1^{\text {hi }}$ macrophages can be visualized throughout the lamina propria (LP), the large layer of connective tissue underlying the epithelium, as well as in the deeper layers of the gut wall, such as the submucosa and muscularis $(17,19,20)$. Macrophages in these distinct sites are reported to express differential levels of CD11c, with $\mathrm{CD} 11 \mathrm{c}^{+}$ and $\mathrm{CD} 11 \mathrm{c}^{-/ \mathrm{lo}} \mathrm{CX} 3 \mathrm{CR} 1^{\text {hi }}$ macrophages enriched in the LP and muscularis, respectively $(18,20,22)$. As discussed in more detail below, additional heterogeneity has been unmasked recently by transcriptional profiling, with discrete subsets of CX3CR $1^{\text {hi }}$ macrophages identifiable based on their expression of CD4 and $\operatorname{Tim} 4(23,24)$.

The recent advances in multi-parameter analysis have also led to the much-needed alignment of analysis of murine and human tissue macrophages. The use of markers such as CD64 and CD14 has meant that the same cells can be characterized across species $(7,9,10,25)$. This has highlighted similarities, but also important differences between mouse and man. For instance, expression of CD4, CD163, CD172a (SIRP $\alpha)$, and CD206 are conserved features of intestinal macrophages across species $(7,9$, $23,24,26)$. However, mature intestinal macrophages in humans express only low levels of the CX3CR1 and CD11c markers found on their murine equivalents. Very recent work has also described potential phenotypic heterogeneity between human LP and muscularis macrophages, with the latter expressing higher levels of CD14 and CD11b (7).

\section{FUNCTIONS OF MACROPHAGES IN INTESTINAL HOMEOSTASIS}

Macrophages play a variety of roles to maintain intestinal homeostasis (Figure 1). Like their counterparts in other tissues, macrophages in the gut wall are avidly phagocytic. However, while being highly bactericidal, phagocytosis by intestinal macrophages does not result in an overt inflammatory response in both mouse and man (see below) $(7,9,25,27,28)$. Consistent with this role, intestinal macrophages display high expression of genes associated with phagocytosis, such as Mertk, Cd206, Gas6, Axl, Cd36, Itgav, and Itgb5 (23, 29). Integrins $\alpha \mathrm{v}$ and $\beta 5$ dimerise to form $\alpha v \beta 5$, which is involved in the uptake of apoptotic cells (29), a process known as efferocytosis (30). Notably, Lys2-directed deletion of integrin $\alpha \mathrm{V}$ results in the accumulation of apoptotic cells in the intestine (31), and Itgb5 deficiency predisposes to increased susceptibility to DSS-induced colitis (29), highlighting a particularly important role for this pathway in this process.

The sub-epithelial positioning of LP macrophages means they are ideally placed to capture and eliminate any bacteria that cross the epithelial barrier. In addition, murine studies have shown that they are able to sample luminal bacteria, involving the formation of transepithelial dendrites (TEDs), cellular processes that cross the epithelial barrier without perturbing tight junctions and epithelial integrity and depend on the CX3CL1-CX3CR1 axis (32-34). A similar process may allow mature CX3CR $1^{\text {hi }}$ macrophages in the upper small bowel to capture dietary materials and is suggested to be involved in the generation of oral tolerance to dietary antigens (35). This requires the induction of antigen specific Tregs in the gut draining mesenteric lymph nodes with gut homing properties $(36,37)$. Given that CX3CR $1{ }^{\text {hi }}$ macrophages do not migrate to draining lymph nodes under normal conditions and naïve $\mathrm{T}$ cells are essentially absent in the $\operatorname{LP}(13,15,38)$, they are unlikely to play a major role in this process. However, they may contribute to the induction of oral tolerance through antigen transfer to migratory $\mathrm{CD} 103^{+}$ $\mathrm{DC}$ via connexin-43-dependent gap junctions (35). Indeed, mice that lack connexin-43 in $\mathrm{CD}_{11 \mathrm{c}^{+}}$cells fail to develop oral tolerance (35). Macrophages have also been proposed to regulate oral tolerance development by supporting Treg maintenance locally in the mucosa $(37,39,40)$. This is thought to involve macrophage-derived IL10, as C $x 3 \mathrm{cr} 1$-mediated deletion of IL10 reduces antigen specific Treg frequencies in a model of oral tolerance $(37,40)$. Interestingly however, deletion of IL10 in macrophages appears to have no impact on the overall abundance of endogenous Treg $(40,41)$. In addition to Tregs, macrophages may also support the induction/maintenance of commensalspecific Th17 cells through IL1 $\beta$ secretion $(42,43)$. Notably, whether maintenance of mucosal $\mathrm{T}$ cells also involves cognate interactions remains to be determined with certainty. Although macrophages are very poor in activating naive T cells compared to DCs (15), their high expression of MHCII suggests that they might be involved in antigen presentation to previously activated $\mathrm{T}$ cells locally in the intestine. By doing so, they could maintain or promote further differentiation of antigen-specific $\mathrm{T}$ 


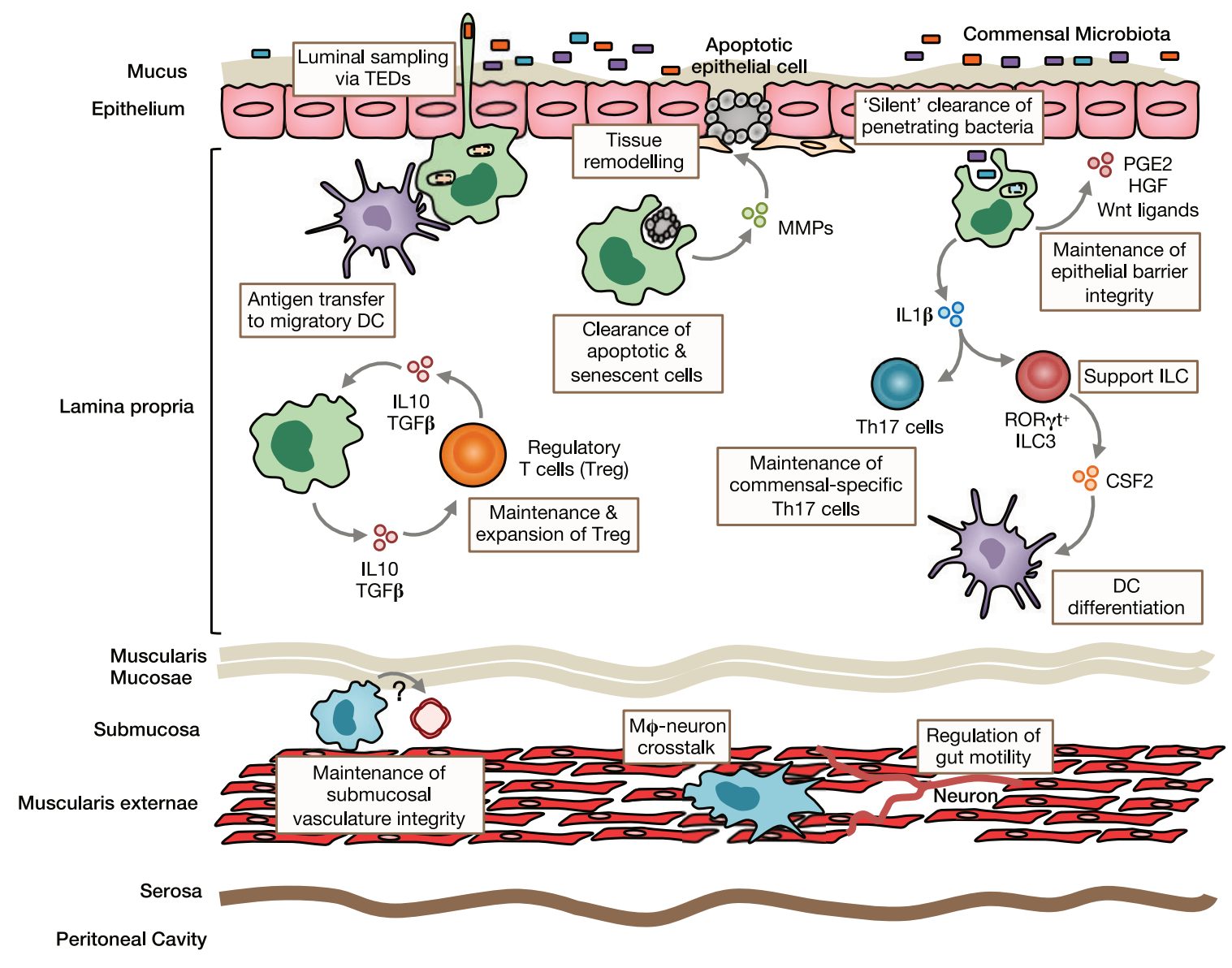

FIGURE 1 | Homeostatic functions of intestinal macrophages. Intestinal lamina propria (LP) macrophages are highly phagocytic and are responsible for clearing apoptotic and senescent epithelial cells. Through their expression of tissue-remodeling metalloproteinases and secretion of factors that stimulate epithelial stem cell renewal, such as prostaglandin E2 (PGE2), hepatocyte growth factor (HGF) and Wnt ligands, they promote epithelial integrity. Their position under the epithelial monolayer and their bactericidal activity, mean LP macrophages are ideally placed to capture and destroy any bacteria that breach the barrier. They may also send cellular processes across the epithelial barrier to sample luminal contents. Macrophages can transfer acquired antigen to migratory dendritic cells (DCs) for presentation to T cells in the draining mesenteric lymph nodes. Through their production of immunoregulatory cytokines, such as IL10 and TGF $\beta$, they maintain and facilitate secondary expansion of regulatory T cells (Tregs) locally in the LP. In a similar manner, they support Th17 cells and ILC3s through their production of IL1 $\beta$, which is induced by exposure to the microbiota or its derivatives. Macrophages are also present in deeper layers of the gut wall, including the submucosa and muscularis externae. Submucosa macrophages are thought to support the integrity of the submucosal vasculature, although the factors involved in this interaction remain unclear. Muscularis macrophages participate in bidirectional crosstalk with sympathetic neurons of the enteric nervous system and influence gut motility.

cells. Consistent with this, Cx3cr1-mediated deletion of MHCII retards the generation/maintenance of antigen-specific Treg after feeding of ovalbumin (OVA) (40). Macrophages may also influence $\mathrm{T}$ cell priming indirectly through their effects on $\mathrm{CDC}$ differentiation. For instance, secretion of IL1 $\beta$ has been shown to enhance ILC3 production of CSF2 (44), which is known to control cDC differentiation in the intestinal LP (45). Notably, most functional analyses have been performed in mice and whether human intestinal macrophages carry out the same roles remains unclear.

While it has been known for many years that macrophages are present in deeper layers of the gut wall (46), only recently has work begun to interrogate their role in intestinal homeostasis. Macrophages in the muscularis are intimately associated with the enteric nervous system and, in mice, appear morphologically and transcriptionally distinct (47). There is bidirectional crosstalk between muscularis macrophages and neurons, where macrophage-derived bone morphogenic protein 2 (BMP2) acts on the BMP receptor (BMPR) expressed by enteric neurons to induce secretion of CSF1, which maintains the muscularis macrophage compartment and stimulates further BMP2 expression $(20,22)$. These interactions regulate smooth muscle contractions, thereby controlling peristalsis, and can be disrupted by broad spectrum antibiotics (22), suggesting the microbiota may regulate gut motility to some extent (48). Macrophages are also found in the submucosa and recent depletion studies have revealed a role for these cells in maintaining the integrity of the submucosal vasculature (47). 
Thus, macrophages fulfill niche-specific functions to meet the local demands of their microenvironment.

\section{ORIGIN OF INTESTINAL MACROPHAGES}

There have been major developments in our understanding of macrophage ontogeny in recent years [see (49) for review]. Traditionally, it was proposed that tissue macrophages were derived from blood monocytes that were replenished in turn by highly proliferative bone marrow (BM) progenitors as part of a linear mononuclear phagocyte system (MPS) $(50,51)$. Geissmann et al. (52) then refined this model demonstrating that the murine monocyte compartment, like its human counterpart (53), is heterogeneous, with subsets defined on the basis of Ly6C expression. In this scheme, $\mathrm{Ly}_{6} \mathrm{C}^{\text {hi }}$ monocytes were shown to preferentially enter tissues under inflammatory conditions, leading to them being described as "inflammatory" monocytes (52). However, as discussed below, Ly6 $\mathrm{C}^{\text {hi }}$ monocytes can also be found in healthy tissues and tend to fulfill the functions classically ascribed to monocytes, therefore these are now referred to as "classical" monocytes. Because they did not enter inflamed tissues, it was proposed that $\mathrm{Ly}_{6} \mathrm{C}^{\mathrm{lo}}$ monocytes were the precursors of tissue resident macrophages (52). However, adoptively transferred $\mathrm{Ly} 6 \mathrm{C}^{\mathrm{lo}}$ monocytes rarely enter healthy tissues, even following diphtheria toxin (DT)-mediated depletion of resident macrophages $(9,17)$. Moreover, recent work has shown that a major function of 'non-classical' Ly6 $\mathrm{C}^{\mathrm{lo}}$ monocytes is to patrol the vasculature and scavenge necrotic endothelial cells (54) rather than acting as a circulating intermediate. Thus, in some respects, Ly6Clo monocytes could be thought of as macrophages of the circulatory system.

Rather than deriving from blood monocytes, recent elegant fate mapping techniques have shown that many tissue macrophages exist independently from conventional haematopoiesis and instead derive from embryonic precursors arising from the yolk sac and/or fetal liver (55-59). For instance, microglia of the central nervous system and epidermal Langerhans cells appear to maintain themselves autonomously through intrinsic longevity and in situ self-renewal throughout adult life (60-64). In contrast, we have shown that although the intestine is initially seeded by embryo-derived macrophages, these are subsequently displaced with age by cells deriving from conventional haematopoiesis (16). Consistently, colonic macrophages, but not microglia or Langerhans cells, are labeled in genetic fate mapping studies exploiting Flt3 or Kit expression to fate map cells deriving from haematopoietic stem cells (HSCs) $(16,55,59,65)$. Moreover, intestinal macrophages are largely replaced by donor cells in the setting of parabiosis and in tissue-protected bone marrow chimeric mice, unlike many other tissue macrophages $(16,56,66-69)$. The finding that macrophage numbers are reduced in the gut wall of unmanipulated adult $\mathrm{Ccr}^{-/-}$mice (9), in whom classical Ly6Chi monocyte egress from BM is defective (70), implies that Ly6C $C^{\text {hi }}$ and not Ly6C lo monocytes are the main precursors of intestinal macrophages in adulthood. In line with this, adoptively transferred classical Ly6 $\mathrm{C}^{\text {hi }}$ monocytes, but not $\mathrm{Ly}_{6 \mathrm{C}} \mathrm{C}^{\mathrm{o}}$ monocytes, give rise to fully mature intestinal macrophages $(9,17,19,71)$. Furthermore, intestinal macrophages are eliminated by repetitive administration of DT to CCR2-DTR transgenic mice $(43,72)$, again indicating that the macrophage pool relies on CCR2-dependent replenishment. Notably, as well as its role in BM egress, homeostatic extravasation of $\mathrm{Ly} 6 \mathrm{C}^{\text {hi }}$ monocytes from the bloodstream into the intestinal mucosa relies on the CCL2-CCR2 axis. This is demonstrated by the failure of both WT monocytes to enter the colonic mucosa of Ccl2-deficient mice and Ccr2-deficient monocytes to enter the mucosa of WT mice in mixed BM chimeras or in the setting of parabiosis $(5,16,73)$.

It is now clear that a monocyte to macrophage differentiation continuum exists in the intestinal LP, a process that has become known as the monocyte "waterfall" $(5,9)$ (Figure 2). At one end are $\mathrm{Ly}_{6 \mathrm{C}}{ }^{\text {hi }} \mathrm{CX} 3 \mathrm{CR} 1^{\text {int }} \mathrm{MHCII}^{-}$("P1") monocytes that appear phenotypically and morphologically similar to their counterparts in blood. Indeed, monocytes in the mucosa retain expression of molecules involved in chemotaxis and extravasation from the circulation, such as CCR2, CD62L, VLA-1, LFA-1, and of course Ly6C (23). These monocytes first acquire MHCII expression ('P2' monocytes), before downregulating Ly6C, and the other markers of extravasation ("P3"macrophages), and finally upregulating CX3CR1 to give rise to fully mature ("P4") macrophages; this process takes around 5-6 days and involves major gene expression changes $(5,9,23)$. Importantly, there is mounting evidence that an analogous "waterfall" is present in the human intestinal mucosa, with classical CD $14^{\text {hi }}$ CCR $2^{+} \mathrm{CD} 11 \mathrm{c}^{\mathrm{hi}}$ monocytes at one end and mature $\mathrm{CD} 14^{\mathrm{lo}} \mathrm{CCR} 2^{-} \mathrm{CD} 11 \mathrm{c}^{\mathrm{lo}}$ macrophages at the other $(7,9,25)$ (Figure 2). In support of this, Bujko et al. have recently used HLA-mismatched duodenal transplants to measure turnover of intestinal macrophages in man, showing that donor $\mathrm{CD} 14^{\mathrm{hi}} \mathrm{CCR} 2{ }^{+} \mathrm{CD} 11 \mathrm{c}^{\mathrm{hi}}$ cells in the graft, which are analogous to P1/P2 cells in mouse, are rapidly replaced by recipient cells. Mature macrophages are also replaced by recipient-derived cells, albeit at slower rates (7). This contrasts markedly with Langerhans cells of the skin epidermis, which have been shown to remain of graft origin in transplanted skin for at least up to 10 years (74). Similarly, alveolar macrophages persist for up to 2 years in transplanted lungs (75). Thus, the limited data available from human transplant studies support the findings from fate mapping studies in mice $(64,65,69,76)$.

Despite the evidence that intestinal macrophages are derived from continuous replenishment by extravasating monocytes, this idea may need to be refined on the basis of very recent findings that long-lived macrophages may be present in the adult intestine $(24,47)$. Longitudinal fate-mapping using Cx3cr1based strategies and tissue-protected BM chimeric mice have identified macrophages that persist for longer than 8 months in the gut wall (47). Two independent studies showed that long-lived macrophages can be identified by Tim 4 and CD4 expression $(24,47)$, which are unaffected by $C c r 2$ deficiency, unlike most of their Tim4- counterparts (24). This is consistent with the long-lived nature of Tim4-expressing macrophages in other tissues, such as the liver and the peritoneal cavity $(69,77)$. Notably, De Schepper and colleagues (47) showed that longlived macrophages were predominantly found in the deeper 


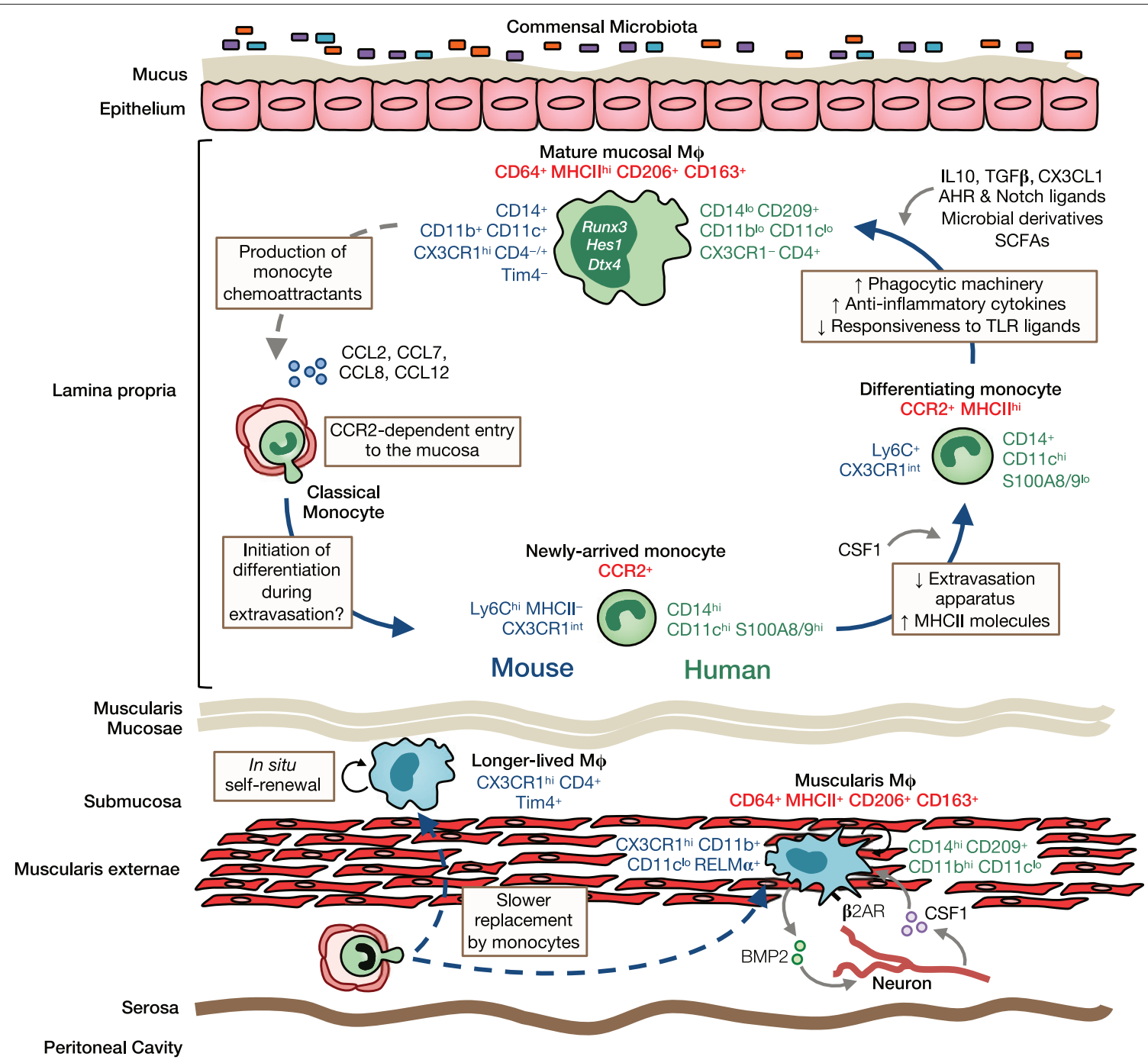

FIGURE 2 | Heterogeneity, origin and differentiation of intestinal macrophages. The majority of mucosal macrophages are replenished by classical monocytes that enter the mucosa in a CCR2-dependent manner and differentiate through a series of intermediaries (mouse-and human-specific markers denoted in blue and green, respectively) to give rise to mature macrophages, which can be identified in both mouse and man as $\mathrm{CD} 64^{+} \mathrm{MHCII}^{\text {hi }} \mathrm{CD} 206^{+} \mathrm{CD}_{163}{ }^{+}$cells (common markers denoted in red). In addition, high levels of CD11b, CD11c, CD14, and CX3CR1 are characteristic features of murine LP macrophages. In contrast, human LP macrophages express only low levels of most of these markers but express high levels of CD209. Once in the mucosa and under cues from the local environment, monocytes first upregulate MHCIl and downregulate molecules involved in extravasation, such as CCR2, LFA-1 and CD62L. They then upregulate phagocytic receptors and increase their production of anti-inflammatory cytokines, as well as becoming hyporesponsive to stimulation through e.g., TLRs. Studies in mice have identified IL10, TGF $\beta$, and CX3CL1 as key factors in promoting macrophage differentiation in the healthy mucosa. Furthermore, exposure to the microbiota and its metabolites is known to influence macrophage differentiation and the rate of their turnover in the LP. Mature macrophages may also regulate their own turnover through secretion of monocyte chemoattractants, such as CCL2, CCL7, CCL8, and CCL12. Longer-lived macrophages may also exist in the murine intestinal mucosa and submucosa, and can be identified by their expression of the phagocytic receptor Tim4. While sharing certain features with their LP counterparts, such as CD64, MHCII, CD206, and CD163 expression, muscularis macrophages have a relatively distinct phenotype. In mouse, they express low levels of CD11c but high levels of the immunoregulatory cytokine RELM $\alpha$, whereas in man, they have high levels of CD14 and CD11b. Muscularis macrophages are acutely dependent on CSF1 and norepinephrine signaling by sympathetic neurons via $\beta 2$ adrenergic receptors ( $\beta 2 A R)$ shapes their differentiation. Monocytes also replenish macrophages of the muscularis, although the rate of replenishment is slower than in the mucosa and a larger proportion of these macrophages are long-lived.

layers of the gut wall, such as the muscularis and submucosa, whereas mucosal macrophages showed high levels of turnover from BM. Importantly, this group also showed that long-lived macrophages derived from both embryonic and BM-derived cells, demonstrating that intrinsic longevity is not an exclusive property of embryo-derived macrophages (47). Thus, in light of these findings, it is clear that the origin of intestinal macrophages is highly dynamic, with embryonic and BM-derived macrophages present alongside one another in each layer of the gut wall, the proportions of which change markedly with age and microbial colonization in a niche-specific manner (see below). Indeed, this brings the gut into line with other tissues, such as the heart 
$(58,78,79)$, lung $(65,69,80)$, dermis $(67)$, and the peritoneal cavity $(69,81,82)$ where short-lived and long-lived macrophages co-exist.

Here it should also be noted that it has never been shown definitely that patrolling $\mathrm{Ly} 6 \mathrm{C}^{\text {lo }}$ monocytes cannot contribute to gut macrophage replenishment. One approach has been to assess macrophage abundance in the gut wall of mice in whom Ly6 $\mathrm{C}^{\text {lo }}$ blood monocytes are markedly reduced, for instance those deficient in $\operatorname{Cx3} \operatorname{cr} 1(37,83)$. However, different groups have reached discordant conclusions on the effect of $\mathrm{C} x 3 \mathrm{cr} 1$ deficiency on intestinal macrophage numbers $(37,83)$. Furthermore, given the high expression of CX3CR1 by intestinal macrophages themselves, effects of $C x 3 c r 1$ deficiency may be due to altered differentiation and/or survival of mature macrophages rather than indicating derivation from Ly6 $\mathrm{C}^{\text {lo }}$ monocytes (see below). More recent work has identified $\mathrm{Nr} 4 \mathrm{al}$ as a master regulator of Ly6 $\mathrm{C}^{\text {lo }}$ monocyte differentiation and survival (84). New tools that specifically target $\mathrm{Nr} 4 \mathrm{al}$ deficiency to monocytes, while sparing its roles in macrophage function, such as those described recently by Hedrick and colleagues (85), will be critical to assess the role of Ly6 $\mathrm{C}^{\text {lo }}$ monocytes in tissue macrophage replenishment under normal physiological conditions and if this changes in the context of disease.

\section{What Controls the Origin of Intestinal Macrophages?}

The exact factors that determine why different tissues contain macrophages of distinct origins remain very poorly understood. Specifically, it is unknown how and why embryonic-derived macrophages persist in the CNS and the epidermis, but fail to persist in significant numbers in the gut mucosa. It has been proposed that this could simply reflect niche accessibility and availability (86) and indeed, there is free accessibility to the mucosa throughout life, whereas the brain and epidermis are separated from the vasculature during development by the blood brain barrier and basement membrane, respectively. However, other tissue macrophages that are not separated from the vasculature by a physical barrier, such as liver Kupffer cells, also exist relatively autonomously, suggesting that tissue accessibility may not be the main factor influencing replacement by blood monocytes (65). In the intestine, monocyte recruitment may be driven by the "physiological inflammation" generated by exposure to antigenic material from the diet or commensal bacteria (87). Indeed, there are now several lines of evidence to demonstrate a key role for the microbiota in influencing macrophage population dynamics in the mucosa. First, major changes in the colonic macrophage compartment are seen following microbial colonization, particularly at the point of weaning where monocyte differentiation through the monocyte "waterfall" becomes established (16). Secondly, macrophage turnover can be reduced by administration of broad spectrum antibiotics, further indicating a role of the commensal microbiota in controlling macrophage turnover (16). Moreover, fewer macrophages are found in the gut wall of germ free mice compared with their SPF counterparts $(16,24$, 88 ). The mucosal microenvironment may actually programme macrophages to orchestrate their own replacement. This is supported by the findings that as intestinal macrophages mature, they progressively upregulate monocyte chemoattractants, such as CCL7, CCL8, and CCL12 (23). As noted above, the microbiota may constitute one stimulus for this differentiation and additional possibilities could include dietary metabolites or the continual mechanical stress generated by peristalsis. Mechanical stress has been suggested to explain the replacement of embryo-derived macrophages in the heart (89) and as well as generating low grade "inflammation," it could simply prevent long term macrophage residence. That differential turnover rates of macrophages are observed in distinct anatomical locales of the gut wall could reflect the fact that particular niches do not support macrophage self-renewal. However, whether distinct macrophage subpopulations display differential rates of proliferation has not been tested experimentally. Thus, while some progress has been made in understanding macrophage turnover dynamics, more work is needed to identify the factors that govern this process.

\section{ENVIRONMENTAL PROGRAMMING OF INTESTINAL MACROPHAGES}

While it is clear that monocytes progress through a defined series of intermediaries to replenish the majority of macrophages in the gut, the molecular factors in the gut environment that imprint the unique phenotypic and functional profile of intestinal macrophages are only starting to be understood. CSF1 is clearly involved in the differentiation and/or survival of intestinal macrophages, as demonstrated by their reduction in Cs $f 1^{\text {op/op }}$ mice, which have a naturally occurring inactivating mutation in the CSF1 gene $(90,91)$, their inability to arise from $C s f 1 r^{-/-}$precursors in a competitive BM chimeric setting (11) and their depletion by anti-CSF1R antibody treatment (22, 92, 93). As described above, upregulation of MHCII is one of the first features of monocyte differentiation in the mucosa of mouse and man $(5,7,9)$. Although it is clear that this occurs independently of the IFN $\gamma$-STAT1 pathway (94), the exact factors that drive upregulation of MHCII remain unclear. Given that this appears to be a common feature of monocytes entering a variety of tissues $(16,59,67,68,95)$, it is plausible that MHCII expression may be triggered by extravasation through the vascular endothelium (68). Indeed monocytes in the colonic mucosa already display major transcriptional differences compared with their counterparts in blood (23), despite appearing phenotypically similar. This is tissue specific, because recently arrived colonic monocytes are also transcriptionally distinct from their phenotypic counterparts in the dermis (23). Once in the mucosa, we have shown that TGF $\beta R$ signaling is essential for the terminal differentiation of macrophages. In particular, upregulation of genes associated with the homeostatic profile of gut macrophages, such as CX3CR1, IL10, and $\alpha \mathrm{v} \beta 5$ integrin relies on the TGF $\beta$-TGF $\beta$ R axis (23). Consistent with this, expression of the Runt-related transcription factor 3 (RUNX3), which regulates TGF $\beta$ signaling, is a unique feature of intestinal macrophages (96). The TGF $\beta$-TGF $\beta$ R axis may 
also regulate macrophage turnover by dampening expression of the monocyte chemoattractant CCL8 by colonic macrophages (23). Although many sources of TGF $\beta$ exist in the mucosa, macrophages themselves may be important, since efferocytosis is known to induce TGF $\beta$ expression in macrophages (97) and, at least in man, macrophages may activate TGF $\beta$ through their expression of integrin $\beta 8$ (98). Indeed, uptake of apoptotic epithelial cells induces an anti-inflammatory programme in intestinal macrophages (99). The epithelium may also support macrophage differentiation through expression of Notch ligands, such as Delta-like and Jagged family members, as mature macrophages express high levels of Hes1 (23), a downstream target of Notch signaling, and their differentiation is disrupted when Notch signaling is ablated (100).

A characteristic feature of mature intestinal macrophages is their hyporesponsiveness to exogenous stimulation $(9,27,101-$ 105), a functional adaptation that allows these cells to exist in this microbe-rich environment. Interestingly, TGF $\beta$ does not appear to be responsible for the unresponsiveness of intestinal macrophages to TLR stimulation in mice (23), whereas this is proposed to be a key role of TGF $\beta$ in the human mucosa $(102,105)$. In contrast, the IL10-IL10R axis plays a fundamental role in the control of macrophage responsiveness in both species. Colonic macrophages from mice in which this axis has been disrupted, either globally or specifically in myeloid cells, have heightened expression of proinflammatory mediators, such as iNOS, IL23, and IL12. As a result, they display overt responsiveness to TLR stimulation and an altered metabolic profile, leading to the development of spontaneous intestinal inflammation $(41,103,106-109)$ that can be rescued by rendering macrophages unresponsive to TLR stimulation through cell specific deletion of the TLR adaptor molecule MyD88 (110). Early onset IBD occurs in patients with polymorphisms in IL10RA and IL10RB genes (111), and in vitro generated monocyte-derived macrophages from these patients respond aggressively to LPS stimulation (108). The exaggerated pro-inflammatory responses in the absence of IL10R signaling may result from a failure to downregulate inflammation potentiating molecules such as TREM-1 and STAT1 $(41,112)$ and/or altered accessibility to pro-inflammatory genes that is normally restricted by IL10dependent chromatin remodeling $(113,114)$. IL10 can also limit pro-inflammatory responses by inducing expression of negative regulators of NF-kB, such as IBNS (115).

The high expression of CX3CR1 by murine intestinal macrophages and their positioning adjacent to CX3CL1producing epithelial cells suggests that the CX3CL1-CX3CR1 axis could also control macrophage differentiation. For instance, CX3CR1 is indispensable for the formation of TEDs that permit luminal sampling by LP macrophages (32-34). Furthermore, CX3cr1-deficient macrophages produce less IL10 (37), suggesting the CX3CL1-CX3CR1 axis promotes the regulatory features of gut macrophages. In line with this, $C \times 3 \mathrm{cr} 1$-deficient mice have been shown to be more susceptible to chemicallyinduced colitis (83), although this has been contested by other reports showing that $C \times 3 c r 1$ deficiency suppresses DSSinduced and $\mathrm{T}$ cell transfer colitis $(32,34)$. However, as noted above, human intestinal macrophages do not express
CX3CR1, raising questions about the general significance of its role.

In addition to influencing their turnover $(16,24)$, the microbiota is required for optimal production of IL1 $\beta$ (42) and IL10 by intestinal macrophages(40, 71, 103), with the latter proposed to rely on autocrine type 1 IFNs (116). Microbial colonization may also contribute to the anergic phenotype of colonic macrophages, since some studies have shown them to display TLR hyperresponsiveness when isolated from germ free mice (103), although this is disputed by others (104). The microbiota may act directly on macrophages, for example through the release of as yet unidentified polysaccharides, such as that recently identified by the Powrie group to be released by $H$. hepaticus (117) or via metabolism of dietary fiber to provide short chain fatty acids (SCFAs), which are known to have wide ranging effects on immune cell function (118). In particular, the SCFA butyrate can repress $I l 6, I l 12 b$, and Nos 2 expression by colonic macrophages (119) and alter their metabolic profile (120), while propionate can dampen macrophage activation in vitro (121). Aryl hydrocarbon receptor (Ahr) ligands derived from the microbiome or the diet may also control macrophage behavior. Consistent with this idea, CD11c $\mathrm{c}^{\mathrm{Cre}}-\mathrm{Ahr} \mathrm{fl}^{\mathrm{fl}}$ mice display heightened susceptibility to DSS-induced colitis, which is attributed to altered Wnt ligand expression by AhR-deficient macrophages and impaired epithelial barrier integrity (122). Thus, multiple environmental factors act in concert to control macrophage differentiation and function in the mucosa.

The equivalent factors controlling macrophage differentiation in the muscularis remain relatively unexplored, although it is clear they are acutely dependent on CSF1R signaling (22). In addition, norepinephrine signaling by sympathetic neurons via $\beta 2$ adrenergic receptors on muscularis macrophages has been reported to shape their tissue protective phenotype (20). Notably, the abundance and patterning of macrophages in the muscularis is not dependent on neuronal signals because they are normal in $\mathrm{Ret}^{-/-}$mice, which lack an enteric nervous system, as well as in patients with Hirschsprung disease (HSCR), where the enteric nervous system is absent from the distal bowel (123).

\section{MONOCYTES AND MACROPHAGES IN INTESTINAL INFLAMMATION}

The monocyte/macrophage compartment alters markedly in both CD and UC, with accumulation of $\mathrm{CD} 14^{\mathrm{hi}} \mathrm{CD} 11 \mathrm{c}^{\mathrm{hi}}$ monocytes/immature macrophages that come to outnumber $\mathrm{CD}^{+} 4^{+} \mathrm{HLA}_{-\mathrm{DR}}{ }^{\text {hi }} \mathrm{CD} 14^{\text {lo }}$ resident macrophages $(9,27,124-$ 127). In contrast to their homeostatic counterparts, these CD $14^{\text {hi }}$ cells in the gut produce pro-inflammatory cytokines and chemokines, such as TNF $\alpha$, IL1 $\beta$, IL6, IL12, IL23, and CCL11 $(125,127)$, display respiratory burst activity (128) and respond in an aberrant manner to commensal bacteria (125). In addition, they express high levels of TREM1, which can potently amplify pro-inflammatory responses (129). Importantly, mucosal healing in IBD patients receiving anti-TNF has been shown to be accompanied by loss of these CD14 ${ }^{\text {hi }}$ cells and accumulation of $\mathrm{CD}^{2} 06^{+}$macrophages, which are thought to 
be pro-reparative (130). Although anti-TNF (adalimumab) has been shown to bind membrane-bound TNF on CD14 ${ }^{+}$intestinal macrophages in $C D$ patients $(131,132)$, whether this triggers a phenotypic switch of existing pro-inflammatory macrophages or if these are replaced by $\mathrm{CD}_{20}{ }^{+}$macrophages remains unclear. Thus, much of the recent work in this field has focussed on understanding the relationship between homeostatic and proinflammatory macrophages and the nature of their precursors, with the ultimate aim of identifying novel therapeutic targets.

Several models of intestinal inflammation, including $\mathrm{T}$ cell transfer, Helicobacter hepaticus-induced and DSS-induced colitis have been used to dissect these processes experimentally. As in humans, all these models show intense accumulation of classical $\left(\right.$ Ly6 $\left.\mathrm{C}^{\mathrm{hi}}\right)$ monocytes, together with their immediate progeny that express intermediate levels of CX3CR1 (P1, P2, P3 subsets-see above) $(5,9,19,71,93,133-135)$. These cells respond in a highly pro-inflammatory manner to TLR stimulation, express reactive oxygen intermediates, produce high levels of IL1 $\beta$, IL6, IL12, IL23, and TNF $\alpha$ and express high levels of TREM1 (5, 9, 17, 19, $71,135)$, again mirroring the processes seen in human IBD. In contrast to these effects on monocytes, the CX3CR 1 hi resident macrophages that persist in colitis retain their anti-inflammatory signature $(9,19,134)$, suggesting they may continue to play an immunoregulatory role even during inflammation (136).

Multiple lines of evidence indicate that Ly6 $\mathrm{C}^{\text {hi }}$ monocytes and their derivatives are of crucial importance in the intestinal pathology. Firstly, neutralization of $\operatorname{IL} 1 \beta$, which is thought to arise predominantly from elicited monocytes, reduces susceptibility to chemically-induced colitis (137). Secondly, colitis development is reduced by selective ablation of Tnfa in Ly6 $\mathrm{C}^{\text {hi }}$ monocytes (17). Whether this reflects direct effects of monocyte-derived $\mathrm{TNF} \alpha$ in tissue pathology is uncertain, as monocyte survival appears to require autocrine $\mathrm{TNF} \alpha$ (138), suggesting that reduced monocyte accumulation in the gut may be the mechanism underlying protection by depletion of TNF $\alpha$. Finally, mice in whom monocyte recruitment to the inflamed mucosa is defective due to deletion or neutralization of CCL2, CCR2 or $\beta_{7}$ integrin are protected from DSS-induced colitis (9, $19,73,133,139,140)$. Importantly, the CCL2-CCR2 axis may also govern monocyte migration in man, where classical monocytes also express CCR2 (141) and elevated levels of its ligands CCL2 and CCL4 are found in IBD mucosa (142). Furthermore, radio-labeled $\mathrm{CD} 14^{\text {hi }}$ classical monocytes have been shown to migrate to actively inflamed regions of IBD mucosa (124). As in the healthy gut, resident macrophages may contribute to this recruitment of monocytes through the release of CCR2 ligands. Nevertheless, it is important to note that CCR2 may not govern monocyte migration in all contexts, as accumulation of Ly $6 \mathrm{C}^{\text {hi }}$ monocytes and their progeny is unaffected by CCR2 deficiency in $H$. hepaticus induced colitis (110) and CCR1 plays a key role in monocyte migration during acute toxoplasmosis (143). Moreover, circulating monocytes in mouse and man express CCR5 (144), which is known to navigate monocytes in certain contexts of inflammation (145), and CCR5 deficient mice develop less inflammation when administered DSS (146). In addition, a unique $\mathrm{CD} 169^{+}$subset of CX3CR $1^{\text {hi }}$ macrophages, located preferentially around intestinal crypts, is expanded during experimental colitis and is important for pathogenesis via its ability to recruit monocytes through secretion of the CCR2/CCR3/CCR5 ligand CCL8 $(147,148)$.

As well as direct effects of elicited monocytes and their products, these cells can recruit and support other innate and adaptive immune effector cells that are important in pathology. For instance, CD $14^{\text {hi }}$ monocytes/macrophages in the IBD mucosa are thought to support pathogenic T cell function through IL23 production and their expression of CD40 and CD80 $(125,149,150)$. Consistent with this idea, CX3CR1 ${ }^{\text {int }}$ monocyte/macrophage-derived IL23 supports effector T cell differentiation during $H$. hepaticus-induced colitis $(93,110,134)$, assisting the generation of highly pathogenic Th17 cells that co-express IFN $\gamma(93,151)$. Elicited monocytes/macrophages may also recruit eosinophils to the inflamed mucosa through the production of CCL11, although whether these play a proinflammatory or pro-resolution function remains unclear (127, 152-154).

\section{Macrophages in Intestinal Infection}

Despite their pathogenic role in sterile intestinal inflammation, ${\text { Ly } 6 C^{\text {hi }}}$ monocytes and their progeny are vital for protective immunity against enteric pathogens. For instance, $C \mathrm{cr} 2^{-/-}$mice are more susceptible to infection with Citrobacter rodentium, a model of enteropathogenic and enterohaemorrhagic E. coli infection in man, and the protozoan parasite Toxoplasma gondii $(155,156)$. This can be restored by transfer of wild type Ly6C $\mathrm{C}^{\text {hi }}$ monocytes. Although depletion of $\mathrm{CCR} 2^{+}$cells in the CCR2DTR mouse leads to enhanced susceptibility to $C$. rodentium (157), it should be noted that this approach deletes both elicited and resident macrophages in the intestine $(43,72,157)$, meaning the specific roles of these individual subsets cannot be distinguished in this model. Nevertheless, macrophages play an important protective role in $C$. rodentium infection via the production of IL1 $\beta$, IL23, and TNF-like ligand 1A (TL1A), triggering IL22 production by ILC3s, which in turn augments local production of the anti-microbial proteins RegIII $\beta$ and RegIII $\gamma$ (157-159), known to be necessary for C. rodentium clearance (160). Moreover, through their production of IL12 and IL23, macrophages support the differentiation of IFN $\gamma$ and IL17producing effector T cells (161). Whether this occurs exclusively in the mucosa or if Ly6 $\mathrm{C}^{\text {hi }}$ monocyte-derived cells leave the mucosa to contribute to $\mathrm{T}$ cell priming in the lymph nodes remains a matter of debate and may depend on the nature of the inflammatory insult $(162,163)$. In addition to their proinflammatory roles, elegant work from the Belkaid lab has shown that Ly $6 \mathrm{C}^{\text {hi }}$ monocytes can also exert regulatory functions. During acute toxoplasmosis, elicited Ly6C $\mathrm{C}^{\text {hi }}$ monocytes respond to the microbiota by producing PGE2 and IL10 that protect against immunopathology by inhibiting neutrophil function (164). As a result, $\mathrm{Ccr} 2^{-/-}$mice show enhanced susceptibility to this model of infection (156). Thus, it is clear that monocytes play a multifaceted role in the inflamed mucosa.

Until now, we have considered macrophage function in Th1 and/or Th17-dominated forms of inflammation, but they also participate in the Th2-mediated protective immune responses generated against intestinal helminth parasites. However, the 
exact role macrophages play may depend on the parasite in question. For instance, while arginase producing, alternatively activated macrophages are critical for the expulsion of the gastrointestinal nematode Heligmosomoides polygyrus bakeri (165-167), inhibition of arginase has no effect on expulsion of Trichuris muris (168). Instead, macrophages are considered to play a more central role in the tissue repair that occurs after T. muris has been expelled. The role of alternatively activated macrophages in expulsion of the nematode Nippostrongylus brasiliensis also remains contentious (169, 170). Interestingly, although macrophage accumulation in Th2 type settings in other tissues is now typically thought to involve in situ proliferation of resident cells under the control of IL4 (171), accumulation of 'alternatively activated' macrophages in the gut of mice with T. muris is dependent on monocyte infiltration (172). Thus, regardless of the nature of the insult, monocyte recruitment appears to be the principal mechanism of bolstering the macrophage reservoir in the gut mucosa.

\section{Monocyte Differentiation in the Inflamed Mucosa}

Why monocytes accumulate during colitis and do not differentiate into anti-inflammatory macrophages as they do in healthy tissue remains unclear. Based on adoptive transfer studies in the DSS-induced model of colitis, we proposed that immature monocytes accumulate due to a breakdown in the normal differentiation process (9). The exact cause of this remains elusive, but may reflect both a loss of factors that normally promote monocyte differentiation, such as IL10 and TGF $\beta$, together with increased levels of pro-inflammatory cytokines that block this process or reduce monocyte half-life. Indeed, high levels of IFN $\gamma$ are found in the IBD mucosa and have been shown to promote the pro-inflammatory features of $\mathrm{CD}^{+} 4^{+}$monocyte/macrophages (125). Consistent with this, deletion of IFN $\gamma \mathrm{R} 1$ or its downstream signaling molecule STAT1 in mice limits the differentiation of proinflammatory $\mathrm{Ly}_{6 \mathrm{C}}{ }^{+} \mathrm{MHCII}^{+}$monocytes in the colon and provides relative protection from DSS-induced colitis (94). IFN $\gamma$ may also act by upregulating negative regulators of the TGFßR pathway, such as Smad7 (173), thus disrupting the pathway by which monocytes normally differentiate into mature, anti-inflammatory macrophages (see above). Finally, the hypoxic nature of the inflamed mucosa may support the differentiation of pro-inflammatory monocytes/macrophages, as myeloid-specific deletion of the hypoxia inducible factor (HIF)-1 $\alpha$ also protects mice from DSS-induced colitis (174).

As well as local programming by the intestinal microenvironment, there is increasing evidence that monocytes arriving in the inflamed mucosa may be inherently different to those during health. Monocytosis is a feature of human and experimental IBD $(175,176)$, and monocytes arriving in the inflamed mucosa already have higher expression of TNF $\alpha$, iNOS, IL6 and STAT1 compared with their homeostatic counterparts $(9,94)$. This may involve "priming" of monocytes in the BM by IFN $\gamma$ derived from NK cells responding to IL12 released from the inflamed intestine, as has been shown to occur in acute toxoplasmosis (177), or through as yet unidentified pathways. Thus, the inflamed mucosal environment may control monocyte fate both locally and through long-range conditioning of $\mathrm{BM}$ precursors.

\section{MONOCYTES/MACROPHAGES DURING RESOLUTION OF INFLAMMATION}

Experimental models of colitis have also allowed characterization of the monocyte/macrophage compartment during the resolution of pathology. Cessation of DSS administration is accompanied by major changes in the macrophage pool, with a massive reduction in CX3CR $1^{\text {int }}$ monocytes/macrophages and restoration of the CX3CR $1^{\text {hi }}$ macrophage subset, together with loss of granulocytes (19). A similar contraction of inflammatory cells is seen following the infectious phase of $H$. hepaticusinduced colitis, although interestingly, eosinophils persist at elevated levels in this model, suggesting they may play a proresolution role (134). Resident intestinal macrophages promote mucosal healing, as colitis is worsened by their depletion (136) or if they are rendered unresponsive to anti-inflammatory cytokines, such as TGF $\beta$ (178). However, whether macrophages elicited by an inflammatory agent also play a pro-restorative role following removal its clearance remains unclear. Interestingly, resolution of inflammation in post-operative ileus is delayed in Ccr $2^{-/-}$mice, suggesting that recruited Ly6 $\mathrm{C}^{\text {hi }}$ monocytes and their derivatives are important for restoration of homeostasis in the muscularis (179).

The fate of the monocytes elicited during inflammation in the repairing mucosa is unclear, although it is assumed that they are cleared by apoptosis, as in other tissues (180). This would be consistent with the increased numbers of apoptotic $\mathrm{CD}^{+}{ }^{+}$cells seen in the healing mucosa of CD and UC patients treated with infliximab (181). An alternative fate of elicited monocytes is that they subsequently convert into mature resident macrophages under the guidance of local cues. While this has been shown to occur during the resolution of inflammation in other tissues, such as the peritoneal cavity (57), it is not known whether it occurs in the repairing mucosa. Moreover, just like in the setting of infection described above, long-range conditioning of monocytes may also occur during inflammation resolution meaning the nature of the monocytes arriving at the repairing mucosa may be intrinsically-distinct. Consistent with this idea, Ikeda et al. (182) have recently shown that a specific subset of Ly6C $\mathrm{C}^{\text {hi }}$ monocytes expressing the regulatory molecule Ym1 can be found during the resolution phase of DSSinduced colitis and their depletion hinders effective mucosal healing.

\section{CONCLUSIONS AND FUTURE PERSPECTIVES}

Several major advances have been made over the last few years in our understanding of intestinal macrophage ontogeny and development, including the identification of some of environmental signals that regulate tissue-specific phenotypes 
and functions. Nevertheless, many aspects of intestinal macrophage biology remain poorly understood. For instance, our understanding of heterogeneity within the intestinal macrophage compartment remains incomplete. The application of single cell technologies, such as single cell RNA sequencing, will continue to provide further insights into macrophage heterogeneity in both mouse and man. This should also allow for further alignment of the ways in which murine and human MPs are characterized and lead to better translation between systems. With the discovery of macrophage subpopulations, it will be important to determine the environmental signals that shape the phenotype, function and longevity of these niche-specific macrophages. Why do some niches promote the longevity of macrophages (e.g., the muscularis externa) whereas others (e.g., the LP) mainly rely on the constant replenishment by BM-derived monocytes? Understanding the cellular interactions between macrophages and their neighboring cells (e.g., stromal cells), the environmental challenges (e.g., antigenic exposure) in particular niches, as well as niche accessibility will be pivotal in answering this question. Importantly, macrophage longevity is not an exclusive property of embryo-derived macrophages and it remains to be determined whether long-lived embryoderived and BM-derived macrophages perform analogous functions or if they have discrete roles in intestinal homeostasis. Another area warranting further investigation is how differences along the intestinal tract, for instance antigenic exposure and

\section{REFERENCES}

1. Hume DA, Perry VH, Gordon S. The mononuclear phagocyte system of the mouse defined by immunohistochemical localisation of antigen F4/80: macrophages associated with epithelia. Anat Rec. (1984) 210:503-12. doi: 10.1002/ar.1092100311

2. McGarry MP, Stewart CC. Murine eosinophil granulocytes bind the murine macrophage-monocyte specific monoclonal antibody F4/80. J Leuk Biol. (1991) 50:471-8.

3. Pabst O, Bernhardt G. The puzzle of intestinal lamina propria dendritic cells and macrophages. Eur J Immunol. (2010) 40:2107-11. doi: 10.1002/eji.201040557

4. Langlet C, Tamoutounour S, Henri S, Luche H, Ardouin L, Gregoire $\mathrm{C}$, et al. CD64 expression distinguishes monocyte-derived and conventional dendritic cells and reveals their distinct role during intramuscular immunization. J Immunol. (2012) 188:1751-60. doi: 10.4049/jimmunol.1102744

5. Tamoutounour S, Henri S, Lelouard H, de Bovis B, de Haar C, van der Woude CJ, et al. CD64 distinguishes macrophages from dendritic cells in the gut and reveals the Th1-inducing role of mesenteric lymph node macrophages during colitis. Eur J Immunol. (2012) 42:3150-66. doi: 10.1002/eji.201242847

6. Gautier EL, Shay T, Miller J, Greter M, Jakubzick C, Ivanov S, et al. Geneexpression profiles and transcriptional regulatory pathways that underlie the identity and diversity of mouse tissue macrophages. Nat Immunol. (2012) 13:1118-28. doi: 10.1038/ni.2419

7. Bujko A, Atlasy N, Landsverk OJB, Richter L, Yaqub S, Horneland $\mathrm{R}$, et al. Transcriptional and functional profiling defines human small intestinal macrophage subsets. J Exp Med. (2018) 215:441-58. doi: $10.1084 /$ jem.20170057

8. Bharat A, Bhorade SM, Morales-Nebreda L, McQuattie-Pimentel AC, Soberanes S, Ridge K, et al. Flow cytometry reveals similarities between lung macrophages in humans and mice. Am J Respir Cell Mol Biol. (2016) 54:147-9. doi: 10.1165/rcmb.2015-0147LE commensal microbiota composition, might impact macrophage development and function. A major effort must be placed on understanding how the monocyte/macrophage compartment changes during acute and chronic inflammation, as well as during inflammation resolution. Do long-lived macrophages persist during and following an inflammatory insult? If so, do they perform specific roles? Given that accumulation of pro-inflammatory monocytes/macrophages is a characteristic feature of IBD, it is vital to understand the precise nature of the molecular factors controlling monocyte/macrophage differentiation under normal physiological conditions, how these change during disease and the relative contribution of local conditioning vs. long-range effects on haematopoiesis. Providing answers to these questions will be vital if macrophages are to be realized as therapeutic targets in IBD.

\section{AUTHOR CONTRIBUTIONS}

Both authors made a substantial, direct and intellectual contribution to the work, and approved it for publication.

\section{ACKNOWLEDGMENTS}

CB is supported by a Sir Henry Dale Fellowship jointly funded by the Wellcome Trust and the Royal Society (Grant Number 206234/Z/17/Z).
9. Bain CC, Scott CL, Uronen-Hansson H, Gudjonsson S, Jansson O, Grip $\mathrm{O}$, et al. Resident and pro-inflammatory macrophages in the colon represent alternative context-dependent fates of the same Ly6Chi monocyte precursors. Mucosal Immunol. (2013) 6:498-510. doi: 10.1038/mi.20 12.89

10. Scott CL, Bain CC, Wright PB, Sichien D, Kotarsky K, Persson $\mathrm{EK}$, et al. CCR2(+)CD103(-) intestinal dendritic cells develop from DC-committed precursors and induce interleukin-17 production by T cells. Mucosal Immunol. (2015) 8:327-39. doi: 10.1038/mi.20 14.70

11. Schlitzer A, McGovern N, Teo P, Zelante T, Atarashi K, Low D, et al. IRF4 transcription factor-dependent $\mathrm{CD} 1 \mathrm{lb}+$ dendritic cells in human and mouse control mucosal IL-17 cytokine responses. Immunity (2013) 38:970-83. doi: 10.1016/j.immuni.2013.04.011

12. Johansson-Lindbom B, Svensson M, Pabst O, Palmqvist C, Marquez G, Forster R, et al. Functional specialization of gut CD103+ dendritic cells in the regulation of tissue-selective T cell homing. J Exp Med. (2005) 202:1063-73. doi: $10.1084 /$ jem.20051100

13. Cerovic V, Houston SA, Scott CL, Aumeunier A, Yrlid U, Mowat AM, et al. Intestinal CD103(-) dendritic cells migrate in lymph and prime effector T cells. Mucosal Immunol. (2013) 6:104-13. doi: 10.1038/mi.2 012.53

14. Coombes JL, Siddiqui KR, Arancibia-Carcamo CV, Hall J, Sun CM, Belkaid $\mathrm{Y}$, et al. A functionally specialized population of mucosal CD103+ DCs induces Foxp3+ regulatory $\mathrm{T}$ cells via a TGF-beta and retinoic aciddependent mechanism. J Exp Med. (2007) 204:1757-64. doi: 10.1084/jem.200 70590

15. Schulz O, Jaensson E, Persson EK, Liu X, Worbs T, Agace WW, et al. Intestinal $\mathrm{CD} 103+$, but not CX3CR1+, antigen sampling cells migrate in lymph and serve classical dendritic cell functions. J Exp Med. (2009) 206:3101-14. doi: 10.1084/jem.20091925

16. Bain CC, Bravo-Blas A, Scott CL, Gomez Perdiguero E, Geissmann F, Henri $\mathrm{S}$, et al. Constant replenishment from circulating monocytes maintains 
the macrophage pool in the intestine of adult mice. Nat Immunol. (2014) 15:929-37. doi: 10.1038/ni.2967

17. Varol C, Vallon-Eberhard A, Elinav E, Aychek T, Shapira Y, Luche H, et al. Intestinal lamina propria dendritic cell subsets have different origin and functions. Immunity (2009) 31:502-12. doi: 10.1016/j.immuni.2009.06.025

18. Bogunovic M, Ginhoux F, Helft J, Shang L, Hashimoto D, Greter M, et al. Origin of the lamina propria dendritic cell network. Immunity (2009) 31:513-25. doi: 10.1016/j.immuni.2009.08.010

19. Zigmond E, Varol C, Farache J, Elmaliah E, Satpathy AT, Friedlander G, et al. Ly6C hi monocytes in the inflamed colon give rise to proinflammatory effector cells and migratory antigen-presenting cells. Immunity (2012) 37:1076-90. doi: 10.1016/j.immuni.2012.08.026

20. Gabanyi I, Muller PA, Feighery L, Oliveira TY, Costa-Pinto FA, Mucida D. Neuro-immune interactions drive tissue programming in intestinal macrophages. Cell (2016) 164:378-91. doi: 10.1016/j.cell.2015.12.023

21. Jung S, Aliberti J, Graemmel P, Sunshine MJ, Kreutzberg GW, Sher A, et al. Analysis of fractalkine receptor CX(3)CR1 function by targeted deletion and green fluorescent protein reporter gene insertion. Mol Cell Biol. (2000) 20:4106-14. doi: 10.1128/MCB.20.11.4106-4114.2000

22. Muller PA, Koscsó B, Rajani GM, Stevanovic K, Berres M-L, Hashimoto $\mathrm{D}$, et al. Crosstalk between muscularis macrophages and enteric neurons regulates gastrointestinal motility. Cell (2014) 158:300-13. doi: 10.1016/j.cell.2014.04.050

23. Schridde A, Bain CC, Mayer JU, Montgomery J, Pollet E, Denecke $B$, et al. Tissue-specific differentiation of colonic macrophages requires TGF $\beta$ receptor-mediated signaling. Mucosal Immunol. (2017) 10:1387-99. doi: 10.1038/mi.2016.142

24. Shaw TN, Houston SA, Wemyss K, Bridgeman HM, Barbera TA, ZangerleMurray T, et al. Tissue-resident macrophages in the intestine are long lived and defined by Tim-4 and CD4 expression. J Exp Med. (2018) 215:1507-18. doi: 10.1084/jem.20180019

25. Bernardo D, Marin AC, Fernández-Tomé S, Montalban-Arques A, Carrasco A, Tristán E, et al. Human intestinal pro-inflammatory CD11chighCCR2+CX3CR1+ macrophages, but not their tolerogenic CD11c-CCR2-CX3CR1- counterparts, are expanded in inflammatory bowel disease. Mucosal Immunol. (2018) 11:1114-26. doi: 10.1038/s41385-018-0030-7

26. Hume DA, Allan W, Hogan PG, Doe WF. Immunohistochemical characterisation of macrophages in human liver and gastrointestinal tract: expression of CD4, HLA-DR, OKM1, and the mature macrophage marker 25F9 in normal and diseased tissue. J Leuk Biol. (1987) 42:474-84.

27. Rugtveit J, Nilsen EM, Bakka A, Carlsen H, Brandtzaeg P, Scott H. Cytokine profiles differ in newly recruited and resident subsets of mucosal macrophages from inflammatory bowel disease. Gastroenterology (1997) 112:1493-505.

28. Mahida YR, Wu KC, Jewell DP. Respiratory burst activity of intestinal macrophages in normal and inflammatory bowel disease. Gut (1989) 30:1362-70.

29. Kumawat AK, Yu C, Mann EA, Schridde A, Finnemann SC, Mowat AM. Expression and characterization of $\alpha \mathrm{v} \beta 5$ integrin on intestinal macrophages. Eur J Immunol. (2018) 48:1181-7.doi: 10.1002/eji.201747318

30. Henson PM. Cell removal: efferocytosis. Annu Rev Cell Dev Biol. (2017) 33:127-44. doi: 10.1146/annurev-cellbio-111315-125315

31. Lacy-Hulbert A, Smith AM, Tissire H, Barry M, Crowley D, Bronson RT, et al. Ulcerative colitis and autoimmunity induced by loss of myeloid alphav integrins. Proc Natl Acad Sci USA. (2007) 104:15823-8. doi: 10.1073/pnas.0707421104

32. Niess JH, Brand S, Gu X, Landsman L, Jung S, McCormick BA, et al. CX3CR1-mediated dendritic cell access to the intestinal lumen and bacterial clearance. Science (2005) 307:254-8. doi: 10.1126/science.1102901

33. Chieppa M, Rescigno M, Huang AY, Germain RN. Dynamic imaging of dendritic cell extension into the small bowel lumen in response to epithelial cell TLR engagement. J Exp Med. (2006) 203:2841-52. doi: $10.1084 /$ jem.20061884

34. Kim KW, Vallon-Eberhard A, Zigmond E, Farache J, Shezen E, Shakhar G, et al. In vivo structure/function and expression analysis of the CX3C chemokine fractalkine. Blood (2011) 118:e156-67. doi: 10.1182/blood-2011-04-348946
35. Mazzini E, Massimiliano L, Penna G, Rescigno M. Oral tolerance can be established via gap junction transfer of fed antigens from CX3CR1(+) Macrophages to CD103(+) dendritic cells. Immunity (2014) 40:248-61. doi: 10.1016/j.immuni.2013.12.012

36. Worbs T, Bode U, Yan S, Hoffmann MW, Hintzen G, Bernhardt G, et al. Oral tolerance originates in the intestinal immune system and relies on antigen carriage by dendritic cells. J Exp Med. (2006) 203:519-27. doi: 10.1084/jem.20052016

37. Hadis U, Wahl B, Schulz O, Hardtke-Wolenski M, Schippers A, Wagner N, et al. Intestinal tolerance requires gut homing and expansion of FoxP3+ regulatory $\mathrm{T}$ cells in the lamina propria. Immunity (2011) 34:237-46. doi: 10.1016/j.immuni.2011.01.016

38. MacDonald TT, Pender SL. Lamina propria T cells. Chem Immunol. (1998) 71:103-17.

39. Murai M, Turovskaya O, Kim G, Madan R, Karp CL, Cheroutre H, et al. Interleukin 10 acts on regulatory $\mathrm{T}$ cells to maintain expression of the transcription factor Foxp3 and suppressive function in mice with colitis. Nat immunol. (2009) 10:1178-84. doi: 10.1038/ni.1791

40. Kim M, Galan C, Hill AA, Wu W-J, Fehlner-Peach H, Song HW, et al. Critical role for the microbiota in CX3CR1+ intestinal mononuclear phagocyte regulation of intestinal $\mathrm{T}$ cell responses. Immunity (2018) 49:151-63.e5. doi: 10.1016/j.immuni.2018.05.009

41. Zigmond E, Bernshtein B, Friedlander G, Walker CR, Yona S, Kim K-W, et al. Macrophage-restricted interleukin-10 receptor deficiency, but not IL-10 deficiency, causes severe spontaneous colitis. Immunity (2014) 40:720-733. doi: 10.1016/j.immuni.2014.03.012

42. Shaw MH, Kamada N, Kim Y-G, Núñez G. Microbiota-induced IL-1 $\beta$, but not IL-6, is critical for the development of steady-state TH17 cells in the intestine. J Exp Med. (2012) 209:251-8. doi: 10.1084/jem.20111703

43. Panea C, Farkas AM, Goto Y, Abdollahi-Roodsaz S, Lee C, Koscsó B, et al. Intestinal monocyte-derived macrophages control commensal-specific Th17 responses. Cell Rep. (2015) 12:1314-24. doi: 10.1016/j.celrep.2015. 07.040

44. Mortha A, Chudnovskiy A, Hashimoto D, Bogunovic M, Spencer SP, Belkaid Y, et al. Microbiota-dependent crosstalk between macrophages and ILC3 promotes intestinal homeostasis. Science (2014) 343:1249288. doi: 10.1126/science.1249288

45. Greter M, Helft J, Chow A, Hashimoto D, Mortha A, Agudo-Cantero J, et al. GM-CSF controls nonlymphoid tissue dendritic cell homeostasis but is dispensable for the differentiation of inflammatory dendritic cells. Immunity (2012) 36:1031-46. doi: 10.1016/j.immuni.2012.03.027

46. Mikkelsen HB, Rumessen JJ. Characterization of macrophage-like cells in the external layers of human small and large intestine. Cell Tissue Res. (1992) 270:273-9.

47. De Schepper S, Verheijden S, Aguilera-Lizarraga J, Viola MF, Boesmans W, Stakenborg N, et al. Self-maintaining gut macrophages are essential for intestinal homeostasis. Cell (2018) 175:400-15.e13. doi: 10.1016/j.cell.2018.07.048

48. Yang M, Fukui H, Eda H, Kitayama Y, Hara K, Kodani M, et al. Involvement of gut microbiota in the association between gastrointestinal motility and 5HT expression/M2 macrophage abundance in the gastrointestinal tract. Mol Med Rep. (2017) 16:3482-8. doi: 10.3892/mmr.2017.6955

49. Ginhoux F, Guilliams M. Tissue-resident macrophage ontogeny and homeostasis. Immunity (2016) 44:439-49. doi: 10.1016/j.immuni.2016.02.024

50. van Furth R, Cohn ZA. The origin and kinetics of mononuclear phagocytes. J Exp Med. (1968) 128:415-35.

51. van Furth R, Cohn ZA, Hirsch JG, Humphrey JH, Spector WG, Langevoort HL. The mononuclear phagocyte system: a new classification of macrophages, monocytes, and their precursor cells. Bull World Health Organ. (1972) 46:845-52.

52. Geissmann F, Jung S, Littman DR. Blood monocytes consist of two principal subsets with distinct migratory properties. Immunity (2003) 19:71-82.

53. Ziegler-Heitbrock HW, Passlick B, Flieger D. The monoclonal antimonocyte antibody My4 stains B lymphocytes and two distinct monocyte subsets in human peripheral blood. Hybridoma (1988) 7:521-7.

54. Carlin LM, Stamatiades EG, Auffray C, Hanna RN, Glover L, VizcayBarrena G, et al. Nr4al-dependent Ly6C(low) monocytes monitor 
endothelial cells and orchestrate their disposal. Cell (2013) 153:362-75. doi: 10.1016/j.cell.2013.03.010

55. Schulz C, Gomez Perdiguero E, Chorro L, Szabo-Rogers H, Cagnard $\mathrm{N}$, Kierdorf $\mathrm{K}$, et al. A lineage of myeloid cells independent of Myb and hematopoietic stem cells. Science (2012) 336:86-90. doi: $10.1126 /$ science.1219179

56. Hashimoto D, Chow A, Noizat C, Teo P, Beasley MB, Leboeuf M, et al. Tissue-resident macrophages self-maintain locally throughout adult life with minimal contribution from circulating monocytes. Immunity (2013) 38:792804. doi: 10.1016/j.immuni.2013.04.004

57. Yona S, Kim K-W, Wolf Y, Mildner A, Varol D, Breker M, et al. Fate mapping reveals origins and dynamics of monocytes and tissue macrophages under homeostasis. Immunity (2013) 38:79-91. doi: 10.1016/j.immuni.2012.12.001

58. Epelman S, Lavine KJ, Beaudin AE, Sojka DK, Carrero JA, Calderon B, et al. Embryonic and adult-derived resident cardiac macrophages are maintained through distinct mechanisms at steady state and during inflammation. Immunity (2014) 40:91-104. doi: 10.1016/j.immuni.2013.11.019

59. Sheng J, Ruedl C, Karjalainen K. Most Tissue-resident macrophages except microglia are derived from fetal hematopoietic stem cells. Immunity (2015) 43:382-93. doi: 10.1016/j.immuni.2015.07.016

60. Alliot F, Godin I, Pessac B. Microglia derive from progenitors, originating from the yolk sac, and which proliferate in the brain. Brain Res Dev Brain Res. (1999) 117:145-52.

61. Ajami B, Bennett JL, Krieger C, Tetzlaff W, Rossi FM. Local self-renewal can sustain CNS microglia maintenance and function throughout adult life. Nat Neurosci. (2007) 10:1538-43. doi: 10.1038/nn2014

62. Ginhoux F, Greter M, Leboeuf M, Nandi S, See P, Gokhan S, et al. Fate mapping analysis reveals that adult microglia derive from primitive macrophages. Science (2010) 330:841-5. doi: 10.1126/science.1194637

63. Hoeffel G, Wang Y, Greter M, See P, Teo P, Malleret B, et al. Adult Langerhans cells derive predominantly from embryonic fetal liver monocytes with a minor contribution of yolk sac-derived macrophages. J Exp Med. (2012) 209:1167-81. doi: 10.1084/jem.20120340

64. Hoeffel G, Chen J, Lavin Y, Low D, Almeida FF, See P, et al. C$\mathrm{Myb}(+)$ erythro-myeloid progenitor-derived fetal monocytes give rise to adult tissue-resident macrophages. Immunity (2015) 42:665-78. doi: 10.1016/j.immuni.2015.03.011

65. Gomez Perdiguero E, Klapproth K, Schulz C, Busch K, Azzoni E, Crozet L, et al. Tissue-resident macrophages originate from yolk-sac-derived erythromyeloid progenitors. Nature (2015) 518:547-51. doi: 10.1038/nature13989

66. Guilliams M, De Kleer I, Henri S, Post S, Vanhoutte L, De Prijck S, et al. Alveolar macrophages develop from fetal monocytes that differentiate into long-lived cells in the first week of life via GM-CSF. J Exp Med. (2013) 210:1977-92. doi: 10.1084/jem.20131199

67. Tamoutounour S, Guilliams M, Montanana Sanchis F, Liu H, Terhorst D, Malosse C, et al. Origins and functional specialization of macrophages and of conventional and monocyte-derived dendritic cells in mouse skin. Immunity (2013) 39:925-38. doi: 10.1016/j.immuni.2013.10.004

68. Jakubzick C, Gautier EL, Gibbings SL, Sojka DK, Schlitzer A, Johnson TE, et al. Minimal differentiation of classical monocytes as they survey steady-state tissues and transport antigen to lymph nodes. Immunity (2013) 39:599-610. doi: 10.1016/j.immuni.2013.08.007

69. Bain CC, Hawley CA, Garner H, Scott CL, Schridde A, Steers NJ, et al. Long-lived self-renewing bone marrow-derived macrophages displace embryo-derived cells to inhabit adult serous cavities. Nat Commun. (2016) 7:ncomms11852. doi: 10.1038/ncomms 11852

70. Serbina NV, Pamer EG. Monocyte emigration from bone marrow during bacterial infection requires signals mediated by chemokine receptor CCR2. Nat Immunol. (2006) 7:311-7. doi: 10.1038/ni1309

71. Rivollier A, He J, Kole A, Valatas V, Kelsall BL. Inflammation switches the differentiation program of Ly6Chi monocytes from antiinflammatory macrophages to inflammatory dendritic cells in the colon. J Exp Med. (2012) 209:139-55. doi: 10.1084/jem.20101387

72. Kinnebrew MA, Buffie CG, Diehl GE, Zenewicz LA, Leiner I, Hohl $\mathrm{TM}$, et al. Interleukin 23 production by intestinal CD103(+)CD11b(+) dendritic cells in response to bacterial flagellin enhances mucosal innate immune defense. Immunity (2012) 36:276-87. doi: 10.1016/j.immuni.2011. 12.011
73. Takada Y, Hisamatsu T, Kamada N, Kitazume MT, Honda H, Oshima $\mathrm{Y}$, et al. Monocyte chemoattractant protein-1 contributes to gut homeostasis and intestinal inflammation by composition of IL-10producing regulatory macrophage subset. J Immunol. (2010) 184:2671-6. doi: 10.4049/jimmunol.0804012

74. Kanitakis J, Morelon E, Petruzzo P, Badet L, Dubernard J-M. Selfrenewal capacity of human epidermal Langerhans cells: observations made on a composite tissue allograft. Exp Dermatol. (2011) 20:145-6. doi: $10.1111 / j .1600-0625.2010 .01146 . x$

75. Eguíluz-Gracia I, Schultz HHL, Sikkeland LIB, Danilova E, Holm AM, Pronk $\mathrm{CJH}$, et al. Long-term persistence of human donor alveolar macrophages in lung transplant recipients. Thorax (2016) 16:2300-11. doi: 10.1136/thoraxjnl-2016-208292

76. Misharin AV, Morales-Nebreda L, Reyfman PA, Cuda CM, Walter JM, McQuattie-Pimentel AC, et al. Monocyte-derived alveolar macrophages drive lung fibrosis and persist in the lung over the life span. J Exp Med. (2017) 214:2387-404. doi: 10.1084/jem.20162152

77. Scott CL, Zheng F, De Baetselier P, Martens L, Saeys Y, De Prijck S, et al. Bone marrow-derived monocytes give rise to self-renewing and fully differentiated Kupffer cells. Nat Commun. (2016) 7:10321. doi: 10.1038/ncomms10321

78. Heidt T, Courties G, Dutta P, Sager HB, Sebas M, Iwamoto Y, et al. Differential contribution of monocytes to heart macrophages in steadystate and after myocardial infarction. Circ Res. (2014) 115:284-95. doi: 10.1161/CIRCRESAHA.115.303567

79. Molawi K, Wolf Y, Kandalla PK, Favret J, Hagemeyer N, Frenzel K, et al. Progressive replacement of embryo-derived cardiac macrophages with age. $J$ Exp Med. (2014) 211:2151-8. doi: 10.1084/jem.20140639

80. Gibbings SL, Thomas SM, Atif SM, McCubbrey AL, Desch AN, Danhorn $\mathrm{T}$, et al. Three unique interstitial macrophages in the murine lung at steady State. Am J Respir Cell Mol Biol. (2017) 57:66-76. doi: 10.1165/rcmb.2016-0361OC

81. Cain DW, O’Koren EG, Kan MJ, Womble M, Sempowski GD, Hopper $\mathrm{K}$, et al. Identification of a tissue-specific, C/EBP $\beta$-dependent pathway of differentiation for murine peritoneal macrophages. J Immunol. (2013) 191:4665-75. doi: 10.4049/jimmunol.1300581

82. Kim K-W, Williams JW, Wang Y-T, Ivanov S, Gilfillan S, Colonna M, et al. MHC II+ resident peritoneal and pleural macrophages rely on IRF4 for development from circulating monocytes. J Exp Med. (2016) 213:1951-9. doi: $10.1084 /$ jem. 20160486

83. Medina-Contreras O, Geem D, Laur O, Williams IR, Lira SA, Nusrat $A$, et al. CX3CR1 regulates intestinal macrophage homeostasis, bacterial translocation, and colitogenic Th17 responses in mice. J Clin Invest. (2011) 121:4787-95. doi: 10.1172/JCI59150

84. Hanna RN, Carlin LM, Hubbeling HG, Nackiewicz D, Green AM, Punt JA, et al. The transcription factor NR4A1 (Nur77) controls bone marrow differentiation and the survival of Ly6C- monocytes. Nat Immunol. (2011) 12:778-85. doi: 10.1038/ni.2063

85. Thomas GD, Hanna RN, Vasudevan NT, Hamers AA, Romanoski CE, McArdle S, et al. Deleting an Nr4al super-enhancer subdomain ablates Ly6Clow monocytes while preserving macrophage gene function. Immunity (2016) 45:975-87. doi: 10.1016/j.immuni.2016.10.011

86. Guilliams M, Scott CL. Does niche competition determine the origin of tissue-resident macrophages? Nat Rev. (2017) 17:451-60. doi: $10.1038 /$ nri.2017.42

87. Fiocchi C. What is "physiological" intestinal inflammation and how does it differ from "pathological" inflammation? Inflamm Bowel Dis. (2008) 14 (Suppl. 2):S77-8. doi: 10.1002/ibd.20618

88. Niess JH, Adler G. Enteric flora expands gut lamina propria CX3CR1+ dendritic cells supporting inflammatory immune responses under normal and inflammatory conditions. J Immunol. (2010) 184:2026-37. doi: 10.4049/jimmunol.0901936

89. Lambrecht B, Guilliams M. Monocytes find a new place to dwell in the niche of heartbreak hotel. J Exp Med. (2014) 211:2136. doi: 10.1084/jem.21111insight1

90. Dai X-M, Zong X-H, Sylvestre V, Stanley ER. Incomplete restoration of colony-stimulating factor 1 (CSF-1) function in CSF-1-deficient Csflop/Csflop mice by transgenic expression of cell surface CSF-1. Blood (2004) 103:1114-23. doi: 10.1182/blood-2003-08-2739 
91. Ryan GR, Dai XM, Dominguez MG, Tong W, Chuan F, Chisholm $\mathrm{O}$, et al. Rescue of the colony-stimulating factor 1 (CSF-1)-nullizygous mouse (Csfl(op)/Csf1(op)) phenotype with a CSF-1 transgene and identification of sites of local CSF-1 synthesis. Blood (2001) 98:74-84. doi: 10.1182/blood.V98.1.74

92. MacDonald KP, Palmer JS, Cronau S, Seppanen E, Olver S, Raffelt $\mathrm{NC}$, et al. An antibody against the colony-stimulating factor 1 receptor depletes the resident subset of monocytes and tissue- and tumor-associated macrophages but does not inhibit inflammation. Blood (2010) 116:3955-63. doi: 10.1182/blood-2010-02-266296

93. Arnold IC, Mathisen S, Schulthess J, Danne C, Hegazy AN, Powrie F. CD11c $(+)$ monocyte/macrophages promote chronic Helicobacter hepaticus-induced intestinal inflammation through the production of IL-23. Mucosal Immunol. (2015) 9:352-63. doi: 10.1038/mi.2015.65

94. Nakanishi Y, Sato T, Takahashi K, Ohteki T. IFN- $\gamma$-dependent epigenetic regulation instructs colitogenic monocyte/macrophage lineage differentiation in vivo. Mucosal Immunol. (2018) 11:871-80. doi: $10.1038 / \mathrm{mi} .2017 .104$

95. Movahedi K, Laoui D, Gysemans C, Baeten M, Stange G, Van den Bossche J, et al. Different tumor microenvironments contain functionally distinct subsets of macrophages derived from Ly6C(high) monocytes. Cancer Res. (2010) 70:5728-39. doi: 10.1158/0008-5472.CAN-09-4672

96. Lavin Y, Winter D, Blecher-Gonen R, David E, Keren-Shaul H, Merad $M$, et al. Tissue-resident macrophage enhancer landscapes are shaped by the local microenvironment. Cell (2014) 159:1312-26. doi: 10.1016/j.cell.2014.11.018

97. Fadok VA, Bratton DL, Konowal A, Freed PW, Westcott JY, Henson PM. Macrophages that have ingested apoptotic cells in vitro inhibit proinflammatory cytokine production through autocrine/paracrine mechanisms involving TGF-beta, PGE2, and PAF. J Clin Invest. (1998) 101:890-8. doi: 10.1172/JCI1112

98. Kelly A, Gunaltay S, McEntee CP, Shuttleworth EE, Smedley C, Houston SA, et al. Human monocytes and macrophages regulate immune tolerance via integrin $\alpha v \beta 8$-mediated TGF $\beta$ activation. J Exp Med. (2018) 215:2725-36. doi: 10.1084/jem.20171491

99. Cummings RJ, Barbet G, Bongers G, Hartmann BM, Gettler K, Muniz L, et al. Different tissue phagocytes sample apoptotic cells to direct distinct homeostasis programs. Nature (2016) 539:565-9. doi: 10.1038/nature20138

100. Ishifune C, Maruyama S, Sasaki Y, Yagita H, Hozumi K, Tomita T, et al. Differentiation of CD11c+ CX3CR1+ cells in the small intestine requires Notch signaling. Proc Natl Acad Sci USA. (2014) 111:5986-91. doi: 10.1073/pnas.1401671111

101. Smythies LE, Sellers M, Clements RH, Mosteller-Barnum M, Meng G, Benjamin WH, et al. Human intestinal macrophages display profound inflammatory anergy despite avid phagocytic and bacteriocidal activity. J Clin Invest. (2005) 115:66-75. doi: 10.1172/JCI19229

102. Smythies LE, Shen R, Bimczok D, Novak L, Clements RH, Eckhoff $\mathrm{DE}$, et al. Inflammation anergy in human intestinal macrophages is due to Smad-induced IkappaBalpha expression and NF-kappaB inactivation. J Biol Chem (2010) 285:19593-604. doi: 10.1074/jbc.M109.0 69955

103. Ueda Y, Kayama H, Jeon SG, Kusu T, Isaka Y, Rakugi H, et al. Commensal microbiota induce LPS hyporesponsiveness in colonic macrophages via the production of IL-10. Int Immunol. (2010) 22:953-62. doi: 10.1093/intimm/dxq449

104. Franchi L, Kamada N, Nakamura Y, Burberry A, Kuffa P, Suzuki S, et al. NLRC4-driven production of IL-1 $\beta$ discriminates between pathogenic and commensal bacteria and promotes host intestinal defense. Nat immunol. (2012) 13:449-56. doi: 10.1038/ni.2263

105. Maheshwari A, Kelly DR, Nicola T, Ambalavanan N, Jain SK, MurphyUllrich J, et al. TGF-beta2 suppresses macrophage cytokine production and mucosal inflammatory responses in the developing intestine. Gastroenterology (2011) 140:242-53. doi: 10.1053/j.gastro.2010.09.043

106. Kuhn R, Lohler J, Rennick D, Rajewsky K, Muller W. Interleukin-10-deficient mice develop chronic enterocolitis. Cell (1993) 75:263-74.

107. Takeda K, Clausen BE, Kaisho T, Tsujimura T, Terada N, Forster I, et al. Enhanced Th1 activity and development of chronic enterocolitis in mice devoid of Stat3 in macrophages and neutrophils. Immunity (1999) 10:39-9.
108. Shouval DS, Biswas A, Goettel JA, McCann K, Conaway E, Redhu NS, et al. Interleukin-10 receptor signaling in innate immune cells regulates mucosal immune tolerance and anti-inflammatory macrophage function. Immunity (2014) 40:706-19. doi: 10.1016/j.immuni.2014.03.011

109. Girard-Madoux MJH, Ober-Blöbaum JL, Costes LMM, Kel JM, Lindenbergh-Kortleve DJ, Brouwers-Haspels I, et al. IL-10 control of $\mathrm{CD} 11 \mathrm{c}+$ myeloid cells is essential to maintain immune homeostasis in the small and large intestine. Oncotarget (2016) 7:32015-30. doi: 10.18632/oncotarget.8337

110. Hoshi N, Schenten D, Nish SA, Walther Z, Gagliani N, Flavell RA, et al. MyD88 signalling in colonic mononuclear phagocytes drives colitis in IL10-deficient mice. Nat Commun. (2012) 3:1120. doi: 10.1038/ncomms2113

111. Glocker EO, Kotlarz D, Boztug K, Gertz EM, Schaffer AA, Noyan F, et al. Inflammatory bowel disease and mutations affecting the interleukin-10 receptor. N Engl J Med. (2009) 361:2033-45. doi: 10.1056/NEJMoa0907206

112. Schenk M, Bouchon A, Birrer S, Colonna M, Mueller C. Macrophages expressing triggering receptor expressed on myeloid cells-1 are underrepresented in the human intestine. J Immunol. (2005) 174:517-24. doi: 10.4049/jimmunol.174.1.517

113. Kobayashi T, Matsuoka K, Sheikh SZ, Russo SM, Mishima Y, Collins C, et al. IL-10 regulates Il12b expression via histone deacetylation: implications for intestinal macrophage homeostasis. J Immunol. (2012) 189:1792-99. doi: 10.4049/jimmunol.1200042

114. Simon JM, Davis JP, Lee SE, Schaner MR, Gipson GR, Weiser M, et al. Alterations to chromatin in intestinal macrophages link IL-10 deficiency to inappropriate inflammatory responses. Eur J Immunol. (2016) 46:1912-25. doi: 10.1002/eji.201546237

115. Hirotani $T$, Lee PY, Kuwata $H$, Yamamoto $M$, Matsumoto $M$, Kawase I, et al. The nuclear IkappaB protein IkappaBNS selectively inhibits lipopolysaccharide-induced IL-6 production in macrophages of the colonic lamina propria. J Immunol. (2005) 174:3650-7. doi: 10.4049/jimmunol.174.6.3650

116. Kole A, He J, Rivollier A, Silveira DD, Kitamura K, Maloy KJ, et al. Type I IFNs regulate effector and regulatory $\mathrm{T}$ cell accumulation and anti-inflammatory cytokine production during $\mathrm{T}$ cell-mediated colitis. J Immunol. (2013) 191:2771-9. doi: 10.4049/jimmunol.13 01093

117. Danne C, Powrie F. Helicobacter hepaticus polysaccharide induces an antiinflammatory response in intestinal macrophages. Microb Cell (2018) 5:20811. doi: $10.15698 / \mathrm{mic} 2018.04 .626$

118. Corrêa-Oliveira R, Fachi JL, Vieira A, Sato FT, Vinolo MAR. Regulation of immune cell function by short-chain fatty acids. Clin Transl Immunol. (2016) 5:e73. doi: $10.1038 /$ cti. 2016.17

119. Chang PV, Hao L, Offermanns S, Medzhitov R. The microbial metabolite butyrate regulates intestinal macrophage function via histone deacetylase inhibition. Proc Natl Acad Sci USA. (2014) 111:2247-52. doi: 10.1073/pnas.1322269111

120. Scott NA, Andrusaite A, Andersen P, Lwason M, Alcon-Giner C, Leclaire $\mathrm{C}$, et al. Antibiotics induce sustained dysregulation of intestinal $\mathrm{T}$ cell immunity by perturbing macrophage homeostasis. Sci Transl Med. (2018). 464:eaao4755. doi: 10.1126/scitranslmed.aao4755

121. Ciarlo E, Heinonen T, Herderschee J, Fenwick C, Mombelli M, Le Roy D, et al. Impact of the microbial derived short chain fatty acid propionate on host susceptibility to bacterial and fungal infections in vivo. Sci Rep. (2016) 6:37944. doi: $10.1038 /$ srep37944

122. Chng SH, Kundu P, Dominguez-Brauer C, Teo WL, Kawajiri K, FujiiKuriyama Y, et al. Ablating the aryl hydrocarbon receptor (AhR) in CD11c+ cells perturbs intestinal epithelium development and intestinal immunity. Sci Rep. (2016) 6:23820. doi: 10.1038/srep23820

123. Avetisyan M, Rood JE, Huerta Lopez S, Sengupta R, Wright-Jin E, Dougherty JD, et al. Muscularis macrophage development in the absence of an enteric nervous system. Proc Natl Acad Sci USA. (2018) 115:4696-701. doi: 10.1073/pnas. 1802490115

124. Grimm MC, Pullman WE, Bennett GM, Sullivan PJ, Pavli P, Doe WF. Direct evidence of monocyte recruitment to inflammatory bowel disease mucosa. $J$ Gastroenterol Hepatol. (1995) 10:387-95.

125. Kamada N, Hisamatsu T, Okamoto S, Chinen H, Kobayashi T, Sato T, et al. Unique CD14 intestinal macrophages contribute to the pathogenesis of 
Crohn disease via IL-23/IFN-gamma axis. J Clin Invest. (2008) 118:2269-80. doi: 10.1172/JCI34610

126. Thiesen S, Janciauskiene S, Uronen-Hansson H, Agace W, Hågerkorp C$\mathrm{M}$, Spee $\mathrm{P}$, et al. CD14hiHLA-DRdim macrophages, with a resemblance to classical blood monocytes, dominate inflamed mucosa in Crohn's disease. $J$ Leukoc Boil. (2013) 95:531-41. doi: 10.1189/jlb.0113021

127. Lampinen M, Waddell A, Ahrens R, Carlson M, Hogan SP. CD14+CD33+ myeloid cell-CCL11-eosinophil signature in ulcerative colitis. J Leukoc Boil. (2013) 94:1061-70. doi: 10.1189/jlb.1212640

128. Mahida YR, Patel S, Gionchetti P, Vaux D, Jewell DP. Macrophage subpopulations in lamina propria of normal and inflamed colon and terminal ileum. Gut (1989) 30:826-34.

129. Schenk M, Bouchon A, Seibold F, Mueller C. TREM-1-expressing intestinal macrophages crucially amplify chronic inflammation in experimental colitis and inflammatory bowel diseases. J Clin Invest. (2007) 117:3097-106. doi: $10.1172 /$ JCI30602

130. Vos ACW, Wildenberg ME, Arijs I, Duijvestein M, Verhaar AP, de Hertogh $\mathrm{G}$, et al. Regulatory macrophages induced by infliximab are involved in healing in vivo and in vitro. Inflamm Bowel Dis. (2012) 18:401-8. doi: 10.1002/ibd.21818

131. Bloemendaal FM, Koelink PJ, van Schie KA, Rispens T, Peters CP, Buskens CJ, et al. TNF-anti-TNF immune complexes inhibit IL-12/IL-23 secretion by inflammatory macrophages via an fc-dependent mechanism. JCrohns Colitis. (2018) 12:1122-30. doi: 10.1093/ecco-jcc/jjy075

132. Atreya R, Neumann H, Neufert C, Waldner MJ, Billmeier U, Zopf Y, et al. In vivo imaging using fluorescent antibodies to tumor necrosis factor predicts therapeutic response in Crohn's disease. Nat Med. (2014) 20:313-18. doi: $10.1038 / \mathrm{nm} .3462$

133. Platt AM, Bain CC, Bordon Y, Sester DP, Mowat AM. An independent subset of TLR expressing CCR2-dependent macrophages promotes colonic inflammation. J Immunol. (2010) 184:6843-54. doi: 10.4049/jimmunol.0903987

134. Bain CC, Oliphant CJ, Thomson CA, Kullberg MC, Mowat AM. Proinflammatory role of monocyte-derived CX3CR1int macrophages in Helicobacter hepaticus-Induced Colitis. Infect Immun. (2018) 86:IAI.0057917. doi: 10.1128/IAI.00579-17

135. Weber B, Saurer L, Schenk M, Dickgreber N, Mueller C. CX3CR1 defines functionally distinct intestinal mononuclear phagocyte subsets which maintain their respective functions during homeostatic and inflammatory conditions. Eur J Immunol. (2011) 41:773-9. doi: 10.1002/eji.201040965

136. Qualls JE, Kaplan AM, Van Rooijen N, Cohen DA. Suppression of experimental colitis by intestinal mononuclear phagocytes. J Leukoc Boil. (2006) 80:802-15. doi: 10.1189/jlb.1205734

137. Seo S-U, Kamada N, Muñoz-Planillo R, Kim Y-G, Kim D, Koizumi Y, et al. Distinct commensals induce interleukin- $1 \beta$ via Nlrp3 inflammasome in inflammatory monocytes to promote intestinal inflammation in response to injury. Immunity (2015) 42:744-55. doi: 10.1016/j.immuni.2015.03.004

138. Wolf Y, Shemer A, Polonsky M, Gross M, Mildner A, Yona S, et al. Autonomous TNF is critical for in vivo monocyte survival in steady state and inflammation. J. Exp Med. (2017) 214:905-17. doi: 10.1084/jem.20160499

139. Schippers A, Muschaweck M, Clahsen T, Tautorat S, Grieb L, Tenbrock K, et al. 37 -Integrin exacerbates experimental DSS-induced colitis in mice by directing inflammatory monocytes into the colon. Mucosal Immunol. (2016) 9:527-38. doi: 10.1038/mi.2015.82

140. Becker F, Kurmaeva E, Gavins FNE, Stevenson EV, Navratil AR, Jin L, et al. A critical role for monocytes/macrophages during intestinal inflammationassociated Lymphangiogenesis. Inflamm Bowel Dis. (2016) 22:1326-45. doi: 10.1097/MIB.0000000000000731

141. Ingersoll MA, Spanbroek R, Lottaz C, Gautier EL, Frankenberger M, Hoffmann R, et al. Comparison of gene expression profiles between human and mouse monocyte subsets. Blood (2010) 115:e10-9. doi: 10.1182/blood-2009-07-235028

142. Smith PD, Smythies LE, Shen R, Greenwell-Wild T, Gliozzi M, Wahl SM. Intestinal macrophages and response to microbial encroachment. Mucosal Immunol. (2010) 4:31-42. doi: 10.1038/mi.2010.66

143. Schulthess J, Meresse B, Ramiro-Puig E, Montcuquet N, Darche S, Bègue B, et al. Interleukin-15-dependent NKp46+ innate lymphoid cells control intestinal inflammation by recruiting inflammatory monocytes. Immunity (2012) 37:108-21. doi: 10.1016/j.immuni.2012.05.013

144. Nieto JC, Zamora C, Cantó E, Garcia-Planella E, Gordillo J, Ortiz MA, et al. CSF-1 regulates the function of monocytes in Crohn's disease patients in remission. Sci Rep. (2017) 7:92. doi: 10.1038/s41598-017-00145-4

145. Tacke F, Alvarez D, Kaplan TJ, Jakubzick C, Spanbroek R, Llodra J, et al. Monocyte subsets differentially employ CCR2, CCR5, and CX3CR1 to accumulate within atherosclerotic plaques. J Clin Invest. (2007) 117:185-94. doi: 10.1172/JCI28549

146. Andres PG, Beck PL, Mizoguchi E, Mizoguchi A, Bhan AK, Dawson T, et al. Mice with a selective deletion of the CC chemokine receptors 5 or 2 are protected from dextran sodium sulfate-mediated colitis: lack of CC chemokine receptor 5 expression results in a NK1.1+ lymphocyte-associated Th2-type immune response in the intestine. J Immunol. (2000) 164:6303-12. doi: 10.4049/jimmunol.164.12.6303

147. Li Q, Wang D, Hao S, Han X, Xia Y, Li X, et al. CD169 Expressing macrophage, a key subset in mesenteric lymph nodes promotes mucosal inflammation in dextran sulfate sodium-induced colitis. Front Immunol. (2017) 8:669. doi: 10.3389/fimmu.2017.00669

148. Asano K, Takahashi N, Ushiki M, Monya M, Aihara F, Kuboki E, et al. Intestinal CD169(+) macrophages initiate mucosal inflammation by secreting CCL8 that recruits inflammatory monocytes. Nat Commun. (2015) 6:7802. doi: $10.1038 /$ ncomms 8802

149. Carlsen HS, Yamanaka T, Scott H, Rugtveit J, Brandtzaeg P. The proportion of $\mathrm{CD} 40+$ mucosal macrophages is increased in inflammatory bowel disease whereas $\mathrm{CD} 40$ ligand $(\mathrm{CD} 154)+\mathrm{T}$ cells are relatively decreased, suggesting differential modulation of these costimulatory molecules in human gut lamina propria. Inflamm Bowel Dis. (2006) 12:1013-24. doi: 10.1097/01.mib.0000234135.43336.72

150. Rugtveit J, Bakka A, Brandtzaeg P. Differential distribution of B7.1 (CD80) and B7.2 (CD86) costimulatory molecules on mucosal macrophage subsets in human inflammatory bowel disease (IBD). Clin Exp Immunol. (1997) 110:104-13.

151. Morrison PJ, Bending D, Fouser LA, Wright JF, Stockinger B, Cooke A, et al. Th17-cell plasticity in Helicobacter hepaticus-induced intestinal inflammation. Mucosal Immunol. (2013) 6:1143-56. doi: 10.1038/mi.2013.11

152. Ahrens R, Waddell A, Seidu L, Blanchard C, Carey R, Forbes E, et al. Intestinal macrophage/epithelial cell-derived CCL11/eotaxin-1 mediates eosinophil recruitment and function in pediatric ulcerative colitis. $J$ Immunol. (2008) 181:7390-9. doi: 10.4049/jimmunol.181.10.7390

153. Waddell A, Ahrens R, Steinbrecher K, Donovan B, Rothenberg ME, Munitz A, et al. Colonic eosinophilic inflammation in experimental colitis is mediated by Ly6C(high) CCR2(+) inflammatory monocyte/macrophage-derived CCL11. J Immunol. (2011) 186:5993-6003. doi: 10.4049/jimmunol.1003844

154. Griseri T, Arnold IC, Pearson C, Krausgruber T, Schiering C, Franchini F, et al. Granulocyte macrophage colony-stimulating factor-activated eosinophils promote interleukin-23 driven chronic colitis. Immunity (2015) 43:187-99. doi: 10.1016/j.immuni.2015.07.008

155. Kim YG, Kamada N, Shaw MH, Warner N, Chen GY, Franchi L,et al. The Nod2 sensor promotes intestinal pathogen eradication via the chemokine CCL2-dependent recruitment of inflammatory monocytes. Immunity (2011) 34:769-80. doi: 10.1016/j.immuni.2011.04.013

156. Dunay IR, Damatta RA, Fux B, Presti R, Greco S, Colonna M, et al. Grl(+) inflammatory monocytes are required for mucosal resistance to the pathogen Toxoplasma gondii. Immunity (2008) 29:306-17. doi: 10.1016/j.immuni.2008.05.019

157. Seo S-U, Kuffa P, Kitamoto S, Nagao-Kitamoto H, Rousseau J, Kim Y-G, et al. Intestinal macrophages arising from CCR2(+) monocytes control pathogen infection by activating innate lymphoid cells. Nat Commun. (2015) 6:8010. doi: $10.1038 /$ ncomms 9010

158. Manta C, Heupel E, Radulovic K, Rossini V, Garbi N, Riedel CU, et al. CX(3)CR1(+) macrophages support IL-22 production by innate lymphoid cells during infection with Citrobacter rodentium. Mucosal Immunol. (2013) 6:177-88. doi: $10.1038 / \mathrm{mi} .2012 .61$

159. Longman RS, Diehl GE, Victorio DA, Huh JR, Galan C, Miraldi ER, et al. CX3CR1+ mononuclear phagocytes support colitis-associated innate 
lymphoid cell production of IL-22. J. Exp Med. (2014) 211:1571-83. doi: $10.1084 /$ jem.20140678

160. Zheng Y, Valdez PA, Danilenko DM, Hu Y, Sa SM, Gong Q, Abbas AR, Modrusan Z, Ghilardi N, de Sauvage FJ, et al. Interleukin-22 mediates early host defense against attaching and effacing bacterial pathogens. Nat Med. (2008) 14:282-9. doi: 10.1038/nm1720

161. Schreiber HA, Loschko J, Karssemeijer RA, Escolano A, Meredith MM, Mucida D, et al. Intestinal monocytes and macrophages are required for $\mathrm{T}$ cell polarization in response to Citrobacter rodentium. J Exp Med. (2013) 210:2025-39. doi: 10.1084/jem.20130903

162. Cerovic V, Bain CC, Mowat AM, Milling SWF. Intestinal macrophages and dendritic cells: what's the difference? Trends Immunol. (2014) 35:270-7. doi: 10.1016/j.it.2014.04.003

163. Bain CC, Mowat AM. Macrophages in intestinal homeostasis and inflammation. Immunol Rev. (2014) 260:102-17. doi: 10.1111/imr.12192

164. Grainger JR, Wohlfert EA, Fuss IJ, Bouladoux N, Askenase MH, Legrand F, et al. Inflammatory monocytes regulate pathologic responses to commensals during acute gastrointestinal infection. Nat Med. (2013) 19:713-21. doi: $10.1038 / \mathrm{nm} .3189$

165. deSchoolmeester ML, Little MC, Rollins BJ, Else KJ. Absence of CC chemokine ligand 2 results in an altered Th1/Th2 cytokine balance and failure to expel Trichuris muris infection. J Immunol. (2003) 170:4693-4700. doi: 10.4049/jimmunol.170.9.4693

166. Filbey KJ, Grainger JR, Smith KA, Boon L, van Rooijen N, Harcus Y, et al. Innate and adaptive type 2 immune cell responses in genetically controlled resistance to intestinal helminth infection. Immunol Cell Biol. (2014) 92:43648. doi: 10.1038/icb.2013.109

167. Schmidt S, Hoving JC, Horsnell WGC, Mearns H, Cutler AJ, Brombacher TM, et al. Nippostrongylus-induced intestinal hypercontractility requires IL-4 receptor alpha-responsiveness by T cells in mice. PLoS ONE (2012) 7:e52211. doi: 10.1371/journal.pone.0052211

168. Bowcutt R, Bell LV, Little M, Wilson J, Booth C, Murray PJ, et al. Arginase1-expressing macrophages are dispensable for resistance to infection with the gastrointestinal helminth Trichuris muris. Parasite Immunol. (2011) 33:411-20. doi: 10.1111/j.1365-3024.2011.01300.x

169. Herbert DR, Hölscher C, Mohrs M, Arendse B, Schwegmann A, Radwanska $M$, et al. Alternative macrophage activation is essential for survival during schistosomiasis and downmodulates $\mathrm{T}$ helper 1 responses and immunopathology. Immunity (2004) 20:623-635. doi: 10.1016/S1074-7613(04)00107-4

170. Zhao A, Urban JF, Anthony RM, Sun R, Stiltz J, van Rooijen N, et al. Th2 cytokine-induced alterations in intestinal smooth muscle function depend on alternatively activated macrophages. Gastroenterology (2008) 135:21725.e1. doi: 10.1053/j.gastro.2008.03.077

171. Jenkins SJ, Ruckerl D, Cook PC, Jones LH, Finkelman FD, Van Rooijen $\mathrm{N}$, et al. Local macrophage proliferation, rather than recruitment from the blood, is a signature of TH2 inflammation. Science (2011) 332:1284-8. doi: $10.1126 /$ science. 1204351

172. Little MC, Hurst RJM, Else KJ. Dynamic changes in macrophage activation and proliferation during the development and resolution of intestinal inflammation. J Immunol. (2014) 193:4684-95. doi: 10.4049/jimmunol.1400502

173. Monteleone G, Boirivant M, Pallone F, MacDonald TT. TGF-beta1 and Smad7 in the regulation of IBD. Mucosal Immunol. (2008) 1(Suppl. 1):S50-3. doi: $10.1038 / \mathrm{mi} .2008 .55$

174. Bäcker V, Cheung F-Y, Siveke JT, Fandrey J, Winning S. Knockdown of myeloid cell hypoxia-inducible factor- $1 \alpha$ ameliorates the acute pathology in DSS-induced colitis. PLoS ONE (2017) 12:e0190074. doi: 10.1371/journal.pone.0190074

175. Mee AS, Berney J, Jewell DP. Monocytes in inflammatory bowel disease: absolute monocyte counts. J Clin Pathol. (1980) 33:917-20.

176. Trottier MD, Irwin R, Li Y, McCabe LR, Fraker PJ. Enhanced production of early lineages of monocytic and granulocytic cells in mice with colitis. Proc Natl Acad Sci USA. (2012) 109:16594-9. doi: 10.1073/pnas.1213854109

177. Askenase MH, Han S-J, Byrd AL, Morais da Fonseca D, Bouladoux $\mathrm{N}$, Wilhelm $\mathrm{C}$, et al. Bone-marrow-resident NK cells prime monocytes for regulatory function during Infection. Immunity (2015) 42:1130-42. doi: 10.1016/j.immuni.2015.05.011

178. Rani R, Smulian AG, Greaves DR, Hogan SP, Herbert DR. TGF-beta limits IL-33 production and promotes the resolution of colitis through regulation of macrophage function. Eur J Immunol. (2011) 41:2000-9. doi: $10.1002 /$ eji.201041135

179. Farro G, Stakenborg M, Gomez-Pinilla PJ, Labeeuw E, Goverse G, Di Giovangiulio M, et al. CCR2-dependent monocyte-derived macrophages resolve inflammation and restore gut motility in postoperative ileus. Gut (2017) 66:2098-109. doi: 10.1136/gutjnl-2016-313144

180. Gautier EL, Ivanov S, Lesnik P, Randolph GJ. Local apoptosis mediates clearance of macrophages from resolving inflammation in mice. Blood (2013) 122:2714-22. doi: 10.1182/blood-2013-01-478206

181. Caprioli F, Bosè F, Rossi RL, Petti L, Viganò C, Ciafardini C, et al. Reduction of CD68+ macrophages and decreased IL-17 expression in intestinal mucosa of patients with inflammatory bowel disease strongly correlate with endoscopic response and mucosal healing following infliximab therapy. Inflamm Bowel Dis. (2013) 19:729-39. doi: 10.1097/MIB.0b013e31828 0292b

182. Ikeda N, Asano K, Kikuchi K, Uchida Y, Ikegami H, Takagi R, et al. Emergence of immunoregulatory $\mathrm{Ym} 1+\mathrm{Ly} 6 \mathrm{Chi}$ monocytes during recovery phase of tissue injury. Sci Immunol. (2018) 3:eaat0207. doi: 10.1126/sciimmunol.aat0207

Conflict of Interest Statement: The authors declare that the research was conducted in the absence of any commercial or financial relationships that could be construed as a potential conflict of interest.

Copyright (๑) 2018 Bain and Schridde. This is an open-access article distributed under the terms of the Creative Commons Attribution License (CC BY). The use, distribution or reproduction in other forums is permitted, provided the original author(s) and the copyright owner(s) are credited and that the original publication in this journal is cited, in accordance with accepted academic practice. No use, distribution or reproduction is permitted which does not comply with these terms. 